\title{
The ins and outs of metal homeostasis by the root nodule actinobacterium Frankia
}

\author{
Teal R Furnholm and Louis S Tisa*
}

\begin{abstract}
Background: Frankia are actinobacteria that form a symbiotic nitrogen-fixing association with actinorhizal plants, and play a significant role in actinorhizal plant colonization of metal contaminated areas. Many Frankia strains are known to be resistant to several toxic metals and metalloids including $\mathrm{Pb}^{2+}, \mathrm{Al}^{+3}, \mathrm{SeO}_{2}, \mathrm{Cu}^{2+}, \mathrm{AsO}_{4}$, and $\mathrm{Zn}^{2+}$. With the availability of eight Frankia genome databases, comparative genomics approaches employing phylogeny, amino acid composition analysis, and synteny were used to identify metal homeostasis mechanisms in eight Frankia strains. Characterized genes from the literature and a meta-analysis of 18 heavy metal gene microarray studies were used for comparison.

Results: Unlike most bacteria, Frankia utilize all of the essential trace elements (Ni, Co, Cu, Se, Mo, B, Zn, Fe, and $\mathrm{Mn}$ ) and have a comparatively high percentage of metalloproteins, particularly in the more metal resistant strains. Cation diffusion facilitators, being one of the few known metal resistance mechanisms found in the Frankia genomes, were strong candidates for general divalent metal resistance in all of the Frankia strains. Gene duplication and amino acid substitutions that enhanced the metal affinity of CopA and CopCD proteins may be responsible for the copper resistance found in some Frankia strains. CopA and a new potential metal transporter, DUF347, may be involved in the particularly high lead tolerance in Frankia. Selenite resistance involved an alternate sulfur importer (CysPUWA) that prevents sulfur starvation, and reductases to produce elemental selenium. The pattern of arsenate, but not arsenite, resistance was achieved by Frankia using the novel arsenite exporter (AqpS) previously identified in the nitrogen-fixing plant symbiont Sinorhizobium meliloti. Based on the presence of multiple tellurite resistance factors, a new metal resistance (tellurite) was identified and confirmed in Frankia.

Conclusions: Each strain had a unique combination of metal import, binding, modification, and export genes that explain differences in patterns of metal resistance between strains. Frankia has achieved similar levels of metal and metalloid resistance as bacteria from highly metal-contaminated sites. From a bioremediation standpoint, it is important to understand mechanisms that allow the endosymbiont to survive and infect actinorhizal plants in metal contaminated soils.
\end{abstract}

Keywords: Actinobacteria, Actinorhizal symbiosis, Bioremediation, Comparative genomics, Metal homeostasis, Metal tolerance

\section{Background}

Frankia is a soil dwelling diazotrophic actinobacteria that forms a symbiosis with a variety of woody dicots, primarily of the nitrogen-fixing clade of Eurosids [1,2]. Actinorhizal plants are found worldwide in a broad range of ecological conditions [3]. The symbiosis with Frankia allows these actinorhizal host plants to colonize harsh environmental terrains including highly contaminated or nutrient-poor

\footnotetext{
*Correspondence: louis.tisa@unh.edu

Department of Molecular, Cellular and Biomedical Sciences, University of New Hampshire, Durham, NH, USA
}

soils [4]. Frankia cultures exhibit elevated levels of tolerance to various heavy metals including $\mathrm{Pb}^{2+}, \mathrm{Al}^{3+}, \mathrm{SeO}_{2}^{3-}$, $\mathrm{Cu}^{2+}, \mathrm{AsO}_{4}$, and $\mathrm{Zn}^{2+}$ [5]. The levels of tolerance to several heavy metals by some Frankia strains are even greater than those of Cupriavidus metallidurans, a wellcharacterized metal-resistant $\beta$-proteobacterium isolated from metal-contaminated sediment [6]. As a potential consequence of their association with plants that frequently grow in poor soils with low buffering capacity, Frankia may be exposed to high levels of metals. Under these low-buffering-soil conditions, metals may be freely 
solubilized from the soil substrate through the action of organic acids, phenolics, and protons produced from both plant and microbial communities [7].

Nearly a quarter of all proteins require a metal cofactor, many of which are toxic at elevated levels [8]. Frankia are highly versatile as a saprophyte, plant symbiont, diazotroph, and producer of secondary metabolites, and therefore require many essential metals for growth [9]. The effects of metals on Frankia physiology have been investigated in culture [10,11], in planta [12,13], and in the field [14-16]. However, little is known about the molecular details and mechanisms of metal resistance and homeostasis by these actinobacteria.

Generally, bacteria have a combination of low and high affinity permeases and ATP-driven metal importers for each of the essential metals [17]. Toxic metals (mercury, lead, cadmium, arsenic, etc.) are often unintentionally imported with the beneficial ones due to similar atomic and aqueous divalent ion radii $[18,19]$. This ion mimicry adds a layer of complexity as cells must not deplete reserves of beneficial metals while exporting their toxic counterparts. Metal export occurs primarily through four mechanisms: (1) cation diffusion facilitators (CDF), (2) resistance-nodulation-cell division (RND) complexes, (3) P-type ATPases, and (4) metal-specific efflux permeases [20]. Many multi-gene transporters are found in a single transcriptional unit (operon), or a separately transcribed functional unit (cassette). An intricate system of metal import, binding, storage, metal cofactor handling, efflux, and cellular redox maintenance mechanisms is needed to maintain metal homeostasis $[18,21]$. This complex system must be responsive to external growth conditions, metabolic state, and various cellular activities (e.g. nitrogen fixation), making metal homeostasis one of the most complex biological processes.

Recent sequencing of several Frankia genomes has provided new insight on the physiology and phylogeny of Frankia [22]. The most striking difference among the first three sequenced Frankia genomes was their sizes, which varied from $5.43 \mathrm{Mbp}$ for a narrow host range Casuarina strain (Frankia sp. strain CcI3) to 9.04 Mbp for a broad host range Elaeagnus strain (EAN1pec) [23]. In recent years, several more Frankia strains have been sequenced [24-31]. Analysis of these genomes confirmed that the Frankia genome size correlates positively to host specificity and biogeography ranges [22,23]. Presently, genome sequences are available for all four Frankia lineages: Cluster 1 "medium and narrow host range" strains $\mathrm{CcI} 3$, ACN14a, CcI6, BMG5.23, Thr, and QA3 [23,26,29-31]; Cluster 2 "uncultured" Frankia datiscae Dg1 [25]; Cluster 3 "broad host range" strains EAN1pec, EUN1f, BMG5.12 and BCU110501 [23,24,27]; and Cluster 4 "atypical" strains Eul1c, CN3 and DC12 [22,24]. Atypical Frankia strains used in this study are unable to fix nitrogen, and two (strains CN3 and DC12) are unable to re-infect their host plant. These databases are providing a wealth of information on secondary metabolism, stress tolerance, symbiosis and nitrogen fixation, having been used successfully in genome mining [32,33], comparative genomics [23,34-37], transcriptomics [38-40] and proteomics approaches [41-44].

For this study, the genomes from the cultured Frankia strains CcI3, ACN14a, QA3, EAN1pec, EuI1c, EUN1f, DC12 and $\mathrm{CN} 3$ were used as the databases. These strains represent three of the four Frankia lineages, have large genome size ranges (5.43 - $9.97 \mathrm{Mbp}$ ), and have diverse levels of association with host plants. In this study, we used bioinformatics and comparative genomics approaches to identify metal homeostasis and toxic metal resistance mechanisms in Frankia.

\section{Results and discussion}

Part 1: Beneficial metals and metal homeostasis

In the absence of genetic tools to assess gene function in Frankia, comparative genomics provides a means of exploring Frankia metal homeostasis and resistance capabilities. A combination of bioinformatics techniques were used to identify metal homeostasis mechanisms in Frankia (Figure 1) including: meta-analysis of 16 gene array studies to identify conserved mechanisms (Additional file 1), phylogenetic grouping with characterized metal homeostasis mechanisms (Additional files 2, 3, 4, 5, 6, 7) gene neighborhood synteny comparison (Additional file 8), and the presence of conserved metal binding residues in protein alignments (Additional file 9). From these analyses, several groups of potential metal homeostasis mechanisms were identified (Additional file 10). Relevance of metal resistance mechanisms was correlated to previously established metal and metalloid tolerance levels [5]. Figure 1 shows a composite diagram of the Frankia resistance/tolerance mechanisms, while the profiles for the individual Frankia genomes are found in the supplemental materials (Additional files 11, 12, 13, 14, 15, 16, 17, 18). Discussed below are the unique combinations of import, chaperone, modification, and export mechanisms involved in metal homeostasis and toxic metal resistance in eight sequenced Frankia strains.

\section{Iron homeostasis}

Iron, zinc, and manganese are essential to most, if not all, organisms [45-47]. Analysis of the Frankia genomes revealed hundreds of genes that encode proteins requiring iron (Table 1). Interestingly, the more metal-resistant Frankia strains and C. metallidurans had significantly higher proportion of iron metalloproteins than other bacteria (Table 1). Three types of iron importers were identified in the Frankia genomes: (1) a high-affinity permease, (2) iron-siderophore $\mathrm{ABC}$ cassettes, and (3) $\mathrm{Fe}^{3+}$ $\mathrm{ABC}$ cassettes. A closely related (33\% identity) homolog of 
the ferrous iron transporter (FTR1) from Saccharomyces cerevisiae was found present in all of the Frankia genomes (Table 2). The Frankia FTR1 homologs were in a possible operon with an iron-transport lipoprotein and a Dyp-type haem peroxidase. These proteins may function collectively for iron assimilation.

All of the Frankia strains also have at least one ABC cassette, either FhuBCD or FepBCDG that functions to transports iron-siderophore complexes (Table 2). Except for strain $\mathrm{CcI} 3$, the fepBCDG operons in the Frankia genomes contained an enterobactin-type permease (COG4997) and a hydroxamate-type permease (COG0609) (Additional file 2). This heterodimeric iron permease complex may allow the transporter to accept a wider variety of iron chelating substances, such as xenosiderophores of the rhizosphere community, providing a competitive advantage [45,48]. The presence of an additional iron importing cassette, either citrate or haem-type, was found in several Frankia strains (Additional file 10). Frankia produces both catecholate and hydroxamate siderophores, making the presence of multiple Fe-siderophore importing $\mathrm{ABC}$ cassettes physiologically relevant $[49,50]$.

During symbiosis, an increased iron acquisition is required by Frankia for both nitrogenase activity and hemoglobin production [51]. Only the symbiotic Frankia strains contain a third type of iron- $A B C$ cassette (FbpABC), which is used for ferric iron import (Additional file 10). The supplementary high affinity iron transporter may help Frankia procure additional iron needed for nitrogenase or for metalloproteins to deal with host-derived phenolic compounds produced during symbiosis [52]. There is a further connection between iron and nitrogen fixation. Nitrogen fixation by Frankia and cyanobacteria requires boron [53], and boron facilitates ferric iron 
Table 1 Predicted number of metalloproteins in Frankia and other bacteria

\begin{tabular}{|c|c|c|c|c|c|c|c|c|c|c|c|c|c|c|}
\hline Metal & [Dom \#] & $\mathrm{Ccl3}$ & $A C N$ & QA3 & EAN1 & EUN & Eul1 & CN3 & $D C 12$ & B sub & $C$ met & $E \mathrm{col}$ & H pyl & M tub \\
\hline $\mathrm{Co}$ & {$[6]$} & 7 & 13 & 12 & 9 & 13 & 15 & 15 & 11 & 11 & 26 & 13 & 6 & 8 \\
\hline $\mathrm{Cu}$ & [31] & 27 & 28 & 34 & 36 & 41 & 31 & 42 & 29 & 23 & 72 & 17 & 6 & 16 \\
\hline $\mathrm{Fe}$ & [174] & 245 & 279 & 328 & 400 & 457 & 445 & 514 & 275 & 179 & 398 & 227 & 77 & 188 \\
\hline Mo & [15] & 7 & 18 & 15 & 18 & 20 & 16 & 20 & 11 & 8 & 28 & 24 & 2 & 12 \\
\hline $\mathrm{Mn}$ & [54] & 74 & 102 & 117 & 156 & 144 & 167 & 185 & 91 & 72 & 102 & 76 & 25 & 99 \\
\hline $\mathrm{Ni}$ & [17] & 25 & 35 & 39 & 38 & 32 & 30 & 28 & 24 & 13 & 29 & 20 & 14 & 14 \\
\hline $\mathrm{Zn}$ & [230] & 174 & 279 & 336 & 388 & 401 & 422 & 483 & 264 & 156 & 305 & 168 & 58 & 215 \\
\hline \multicolumn{2}{|c|}{ Genome a } & 4621 & 6723 & 6546 & 7250 & 7833 & 7262 & 8412 & 5933 & 4354 & 6430 & 4427 & 1749 & 4062 \\
\hline \multicolumn{2}{|c|}{$\% \mathrm{MPs}$} & 12.1 & 11.2 & 13.5 & 14.4 & 14.1 & 15.5 & 15.3 & 11.9 & 10.6 & 14.9 & 12.3 & 10.7 & 13.6 \\
\hline \multicolumn{2}{|c|}{$\% M R$} & 1.06 & 1.06 & 1.06 & 1.06 & 1.06 & 1.06 & 1.06 & 1.06 & 1.06 & 1.06 & 1.06 & 1.06 & 1.06 \\
\hline
\end{tabular}

Proteins with metal ion binding properties were identified using Gene Ontology function search through the Joint Genome Institute - Integrated Microbial Genomes website (https://img.jgi.doe.gov). Identified protein domains for the metalloproteins were used to find orthologs in Frankia and other bacteria including: Bacillus subtilis subtilis 168 (B sub), Cupriavidus metallidurans CH34 (C met), Escherichia coli K12- W3110 (E col), Helicobacter pylori B8 (H pyl), Mycobacterium tuberculosis H37Rv (M tub), and Streptomyces viridochromogenes DSM 40736 (S vir). Genomes with significant (>1 S.D. from average) metalloprotein content, normalized to the genome size, are in bold. \% MPs = percentage of total metalloproteins in the genome. \%MR = percent metal resistance genes (binding, detoxification, and export) in the genome. [Dom \#] = Number of unique protein families (pfam) or ortholog clusters (COG) that bind the indicated metal.

a. Total number of protein coding genes in each genome.

transport via FbpABC [54]. Increased oxidative stress occurs from the import of the more toxic ferric-iron and from the host immunity during symbiosis $[52,55]$. The nitrogenase enzyme needs iron. but is permanently inactivated once oxidized During nitrogen fixation, the iron cofactored superoxide dismutase (SodF) is up-regulated in Frankia [56]. This link between iron and nitrogen-fixation explains why SodF is only found in the $\mathrm{N}_{2}$-fixing Frankia strains (Additional file 10). The iron chaperone, IscA, is involved in the production of iron-sulfur clusters and was found in all of the Frankia genomes (Table 2). The nitrogen-fixing strains have a second copy of the IscA, which is likely used for the Fe-S containing nitrogenase complex [57]. Once inside the cell, iron is removed from siderophores and reduced to ferrous iron by the reductase FhuF [45]. Orthologs of FhuF are 3X more abundant in the nitrogen fixing strains (Table 2), and possibly work in concert with the ferric iron $\mathrm{ABC}$ transporters found only in these strains. The ferrous iron is incorporated into proteins by ferrochelatase or placed into bacterioferritin (Bfr) or Dps storage complexes [48]. The ferrous iron efflux protein (FieF) is in the family of cation diffusion facilitators (CDF) which may export both divalent zinc and iron [58]. FieF may help alleviate iron stress in Frankia by exporting surplus iron.

\section{Zinc and manganese homeostasis}

All of the Frankia genomes have hundreds of zinc and manganese metalloproteins, nearly as many as for iron (Table 1). The necessity of zinc is well established, both as a structural component of macromolecules and as a cofactor in enzymatic reactions, with up to $10 \%$ of proteins in a genome requiring a zinc cofactor $[59,60]$. Manganese, as an antioxidant in the cytoplasm, helps detoxify oxygen radicals as a cofactor for SodN, and replaces the more toxic iron when cells are under oxidative stress $[46,61]$. Zinc and manganese are structural analogs and share transport mechanisms [46]. While the natural resistance-associated macrophage protein (NRAMP)-type manganese permease $(\mathrm{MntH})$ is found in closely related actinomycetes including Geodermatophilus and Mycobacterium, the $m n t H$ genes were conspicuously absent in Frankia genomes. However, the Frankia genomes contained low affinity magnesium permeases, CorA and MgtE (Table 2), which transport several types of divalent cations including zinc [62]. Additionally, Frankia sp. strain CcI3 and F. alni strain ACN14a contained the zinc-iron permease (ZIP).

All of the Frankia genomes possessed high-affinity Mnt/ Znu-type $\mathrm{ABC}$ transporter. Under low nutrient conditions, this high affinity Mnt/Znu - type ABC cassette functions for both $\mathrm{Mn}^{2+}$ and $\mathrm{Zn}^{2+}$ uptake, as seen with $M$. tuberculosis [63]. There is little understanding of the appropriate placement of zinc into metalloproteins once it enters the cytoplasm. Certain GTPases are metallochaperones, some of which deliver nickel or cobalt (UreJ/HypB and CobW, respectively), while other proteins (YciC) are suspected to deliver zinc to metalloproteins [64]. The Frankia homologs of these GTPases (COG0523) fall phylogenetically between CobW/YjiA and YciC, both of which are zinc chaperones (Additional file 3).

Some Frankia strains are resistant up to $8 \mathrm{mM}$ zinc (data not shown), which is a level comparable to the metal resistant $C$. metallidurans isolated from a zinc contaminated site [6]. The absence of zinc-type ATPases (EC:3.6.3.3 and 3.6.3.5) and heavy metal RND (HMERND) exporters in the Frankia genomes indicates their reliance on other resistance mechanisms. In addition to FieF, two more cation diffusion facilitators $(\mathrm{CzcD}$ and 
Table 2 Abundance of homeostasis mechanisms in Frankia

\begin{tabular}{|c|c|c|c|c|c|c|c|c|c|c|c|c|c|}
\hline \multicolumn{14}{|c|}{ Mechanism Counts in Selected Genomes } \\
\hline & Symbol & $\begin{array}{l}\text { Frankia } \\
\text { sp. strain } \\
\text { Ccl3 }\end{array}$ & $\begin{array}{c}\text { Frankia } \\
\text { alni } \\
\text { ACN14a }\end{array}$ & $\begin{array}{l}\text { Frankia } \\
\text { sp. strain } \\
\text { QA3 }\end{array}$ & $\begin{array}{l}\text { Frankia sp. } \\
\text { strain } \\
\text { EUN1f }\end{array}$ & $\begin{array}{l}\text { Frankia sp. } \\
\text { strain } \\
\text { EAN1pec }\end{array}$ & $\begin{array}{c}\text { Frankia } \\
\text { sp. strain } \\
\text { Eul1c }\end{array}$ & $\begin{array}{l}\text { Frankia } \\
\text { sp. strain } \\
\text { CN3 }\end{array}$ & $\begin{array}{c}\text { Frankia } \\
\text { sp. strain } \\
\text { DC12 }\end{array}$ & S. viridochromogenes & B. subtilis 168 & C. metallidurans & $\begin{array}{c}\text { E. coli } \\
\text { K12- } \\
\text { W3110 }\end{array}$ \\
\hline \multirow{9}{*}{$\begin{array}{l}\text { Import } \\
\text { permeases }\end{array}$} & CbtA & 1 & 1 & 1 & 1 & 1 & 1 & 1 & 1 & 1 & 0 & 0 & 0 \\
\hline & CorA & 1 & 2 & 1 & 1 & 1 & 1 & 2 & 1 & 3 & 1 & 2 & 1 \\
\hline & Ftr1 & 1 & 1 & 1 & 1 & 1 & 2 & 1 & 1 & 1 & 1 & 1 & 0 \\
\hline & MgtE & 1 & 1 & 1 & 1 & 1 & 1 & 1 & 1 & 1 & 1 & 0 & 0 \\
\hline & NhlF & 1 & 1 & 1 & 0 & 0 & 1 & 1 & 1 & 0 & 0 & 1 & 0 \\
\hline & Pit & 0 & 1 & 1 & 1 & 0 & 0 & 1 & 0 & 3 & 1 & 1 & 0 \\
\hline & SulP & 3 & 2 & 2 & 4 & 3 & 2 & 3 & 2 & 3 & 2 & 6 & 1 \\
\hline & Ycn」 & 1 & 1 & 1 & 1 & 1 & 1 & 1 & 1 & 2 & 1 & 0 & 0 \\
\hline & Zip & 2 & 1 & 0 & 0 & 0 & 0 & 0 & 1 & 0 & 0 & 1 & 1 \\
\hline \multirow{8}{*}{$\begin{array}{l}\text { Import } \\
\text { cassettes }\end{array}$} & CbiMNOQ & 0 & 0 & 0 & 1 & 1 & 0 & 0 & 0 & 2 & 1 & 0 & 0 \\
\hline & CysPUWA & 0 & 0 & 0 & 1 & 0 & 1 & 1 & 1 & 0 & 0 & 1 & 1 \\
\hline & FbpABC & 1 & 0 & 1 & 2 & 2 & 1 & 0 & 0 & 0 & 0 & 0 & 1 \\
\hline & FepBCDG & 0 & 1 & 1 & 1 & 1 & 1 & 2 & 1 & 2 & 0 & 1 & 1 \\
\hline & FhuBCD & 1 & 2 & 1 & 0 & 1 & 0 & 0 & 1 & 1 & 5 & 1 & 2 \\
\hline & $\begin{array}{l}\text { Mnt/ } \\
\text { ZnuABC }\end{array}$ & 1 & 1 & 1 & 1 & 1 & 1 & 1 & 1 & 1 & 2 & 0 & 1 \\
\hline & Mod ABC & 1 & 1 & 1 & 1 & 1 & 1 & 1 & 1 & 1 & 1 & 1 & 1 \\
\hline & PstABCS & 1 & 1 & 1 & 1 & 1 & 1 & 1 & 1 & 1 & 1 & 1 & 1 \\
\hline \multirow{13}{*}{$\begin{array}{l}\text { Chaperones } \\
\text { storage }\end{array}$} & BFR & 1 & 3 & 3 & 2 & 2 & 2 & 2 & 1 & 1 & 0 & 2 & 1 \\
\hline & CbiX & 1 & 1 & 1 & 1 & 2 & 1 & 1 & 1 & 3 & 1 & 1 & 0 \\
\hline & ChID & 1 & 1 & 3 & 4 & 2 & 2 & 4 & 2 & 0 & 0 & 1 & 0 \\
\hline & Chll & 2 & 2 & 2 & 3 & 3 & 2 & 2 & 2 & 1 & 0 & 2 & 1 \\
\hline & CobN & 1 & 1 & 3 & 2 & 1 & 1 & 2 & 3 & 2 & 0 & 0 & 0 \\
\hline & CobW & 0 & 1 & 1 & 1 & 1 & 1 & 1 & 1 & 1 & 1 & 3 & 2 \\
\hline & CopZ & 1 & 1 & 1 & 3 & 3 & 1 & 2 & 1 & 2 & 1 & 7 & 1 \\
\hline & Fe-DPS & 1 & 1 & 1 & 1 & 1 & 1 & 1 & 1 & 2 & 2 & 1 & 1 \\
\hline & FhuF & 3 & 3 & 3 & 3 & 4 & 1 & 1 & 1 & 4 & 0 & 3 & 1 \\
\hline & НypA & 2 & 2 & 2 & 2 & 2 & 1 & 1 & 1 & 1 & 0 & 2 & 2 \\
\hline & НурВ & 2 & 2 & 2 & 1 & 1 & 0 & 1 & 0 & 1 & 0 & 2 & 1 \\
\hline & IscA & 2 & 2 & 2 & 2 & 2 & 1 & 1 & 1 & 1 & 1 & 2 & 4 \\
\hline & ModG & 1 & 2 & 2 & 2 & 2 & 0 & 0 & 0 & 1 & 0 & 1 & 1 \\
\hline
\end{tabular}


Table 2 Abundance of homeostasis mechanisms in Frankia (Continued)

\begin{tabular}{|c|c|c|c|c|c|c|c|c|c|c|c|c|c|}
\hline & MrnA & 0 & 1 & 1 & 0 & 1 & 1 & 1 & 0 & 1 & 0 & 0 & 0 \\
\hline & SenC & 2 & 3 & 3 & 3 & 2 & 1 & 1 & 2 & 1 & 1 & 3 & 0 \\
\hline & UreG & 1 & 1 & 1 & 1 & 1 & 1 & 1 & 1 & 1 & 0 & 1 & 0 \\
\hline \multirow[t]{12}{*}{ Modification } & ArsC & 0 & 1 & 1 & 0 & 1 & 0 & 0 & 1 & 1 & 3 & 4 & 3 \\
\hline & GSH & 0 & 0 & 0 & 0 & 1 & 1 & 1 & 0 & 0 & 0 & 1 & 1 \\
\hline & $\mathrm{MSH}$ & 1 & 1 & 1 & 1 & 1 & 1 & 1 & 1 & 1 & 0 & 0 & 0 \\
\hline & NasC & 1 & 0 & 0 & 0 & 0 & 0 & 2 & 0 & 1 & 1 & 1 & 0 \\
\hline & NirB & 2 & 1 & 1 & 1 & 1 & 1 & 2 & 1 & 2 & 2 & 2 & 1 \\
\hline & NirD & 1 & 1 & 1 & 1 & 1 & 1 & 2 & 1 & 1 & 1 & 1 & 1 \\
\hline & PbrB & 1 & 1 & 1 & 1 & 1 & 1 & 1 & 1 & 1 & 1 & 3 & 1 \\
\hline & NirA & 1 & 1 & 1 & 1 & 1 & 1 & 1 & 1 & 1 & 0 & 0 & 0 \\
\hline & SorA & 0 & 0 & 0 & 2 & 0 & 1 & 1 & 0 & 0 & 0 & 1 & 0 \\
\hline & TrxA & 1 & 1 & 2 & 2 & 1 & 2 & 2 & 1 & 2 & 1 & 2 & 1 \\
\hline & $\operatorname{TrxB}$ & 2 & 4 & 5 & 3 & 2 & 5 & 4 & 3 & 3 & 4 & 5 & 1 \\
\hline & UppP & 2 & 3 & 3 & 3 & 3 & 2 & 2 & 1 & 1 & 1 & 1 & 1 \\
\hline \multirow[t]{17}{*}{ Exporters } & ACR3 & 0 & 1 & 1 & 0 & 1 & 0 & 0 & 0 & 1 & 1 & 1 & 0 \\
\hline & AqpS & 1 & 2 & 2 & 2 & 1 & 3 & 2 & 2 & 3 & 1 & 2 & 2 \\
\hline & CadD & 0 & 0 & 1 & 1 & 1 & 0 & 0 & 0 & 0 & 0 & 0 & 0 \\
\hline & ChrA & 1 & 0 & 0 & 0 & 0 & 1 & 1 & 2 & 1 & 2 & 5 & 0 \\
\hline & CopA & 1 & 1 & 1 & 2 & 3 & 1 & 3 & 2 & 2 & 1 & 4 & 1 \\
\hline & CopC & 2 & 2 & 2 & 3 & 2 & 2 & 2 & 3 & 2 & 1 & 2 & 1 \\
\hline & CopD & 2 & 2 & 2 & 2 & 2 & 3 & 2 & 2 & 3 & 1 & 2 & 1 \\
\hline & CorC & 2 & 3 & 3 & 3 & 3 & 2 & 2 & 2 & 4 & 5 & 5 & 6 \\
\hline & $\mathrm{CzcD}$ & 1 & 1 & 1 & 1 & 1 & 1 & 1 & 1 & 1 & 1 & 1 & 1 \\
\hline & DUF347 & 2 & 4 & 1 & 2 & 1 & 3 & 3 & 3 & 0 & 0 & 7 & 0 \\
\hline & FieF & 1 & 1 & 0 & 0 & 1 & 1 & 1 & 1 & 1 & 3 & 1 & 1 \\
\hline & Nark & 1 & 1 & 1 & 1 & 1 & 2 & 2 & 1 & 1 & 2 & 3 & 2 \\
\hline & RenA & 0 & 0 & 0 & 1 & 1 & 0 & 1 & 0 & 0 & 0 & 0 & 1 \\
\hline & TauZ & 0 & 0 & 0 & 0 & 0 & 1 & 1 & 1 & 0 & 0 & 2 & 1 \\
\hline & TehA & 0 & 0 & 0 & 0 & 0 & 1 & 0 & 0 & 1 & 0 & 0 & 1 \\
\hline & TerC & 1 & 1 & 1 & 1 & 1 & 1 & 1 & 1 & 1 & 3 & 4 & 4 \\
\hline & ZnT-9 & 1 & 2 & 2 & 1 & 1 & 1 & 2 & 1 & 2 & 0 & 0 & 0 \\
\hline
\end{tabular}


ZnT-9) were present in all of the Frankia genomes and probably contribute to zinc resistance (Figure 2). CzcD is found up-regulated in both gram-positive and gramnegative bacteria for a variety of metal cations (e.g. $\mathrm{Zn}^{2+}$, $\left.\mathrm{Cd}^{2+}, \mathrm{Cu}^{2+}\right)$ and, being under control of ArsR, it is also up-regulated by arsenic oxyanions (Additional file 1). The $\mathrm{CzcD}$ orthologs found in the Frankia genomes are highly similar to those found in the array studies (Figure 2). As one of the few orthologs to known metal export mechanisms, CzcD may contribute significantly to Frankia metal resistance. Unlike $\mathrm{CzcD}$, the exact function of the other CDF transporter (ZnT-9) remains elusive [65].

Due to its ionic mimicry of zinc, cadmium likely follows the same route into and out of the cell, being imported through general ion permeases (e.g. CorA) and exported via cation diffusion facilitators [59]. CadD, which is involved in low-level cadmium resistance [66], was present in three Frankia genomes, but its contribution to metal resistance is not clear based on metal resistance patterns alone (Table 2). Manganese has low toxicity and there are few known bacterial manganese-specific exporters [46]. Because of its similarity to zinc and iron, Frankia probably exports manganese via cation diffusion facilitators, as was demonstrated for Arabidopsis and Streptococcus pneumoniae $[67,68]$.

\section{Nickel and cobalt homeostasis}

Several other trace elements act as cofactors for hundreds of metalloproteins, including: nickel [69], cobalt [70], copper [71], molybdenum [72], and selenium $[73,74]$. Although these trace elements are used by most organisms, only $17 \%$ of them use all five as cofactors [47]. All of the Frankia strains appear to utilize all five trace elements (Table 1), with each strain having at least three different metalloenzymes per element (data not shown). Nickel import occurs through active transport via the nickel $A B C$ cassette (NikABCDER) or by high (HoxN/NhlF) and low affinity (CorA and MgtE) permeases [61]. All of the Frankia genomes, except strain EUN1f, have a high affinity nickel permease (NhlF) (Table 2). Additionally, the Frankia genomes possessed a wide range (4 to 23) of the binding component (nikA) genes and multiple combinations of the remaining subunits (nikBCDE) (Additional file 10).

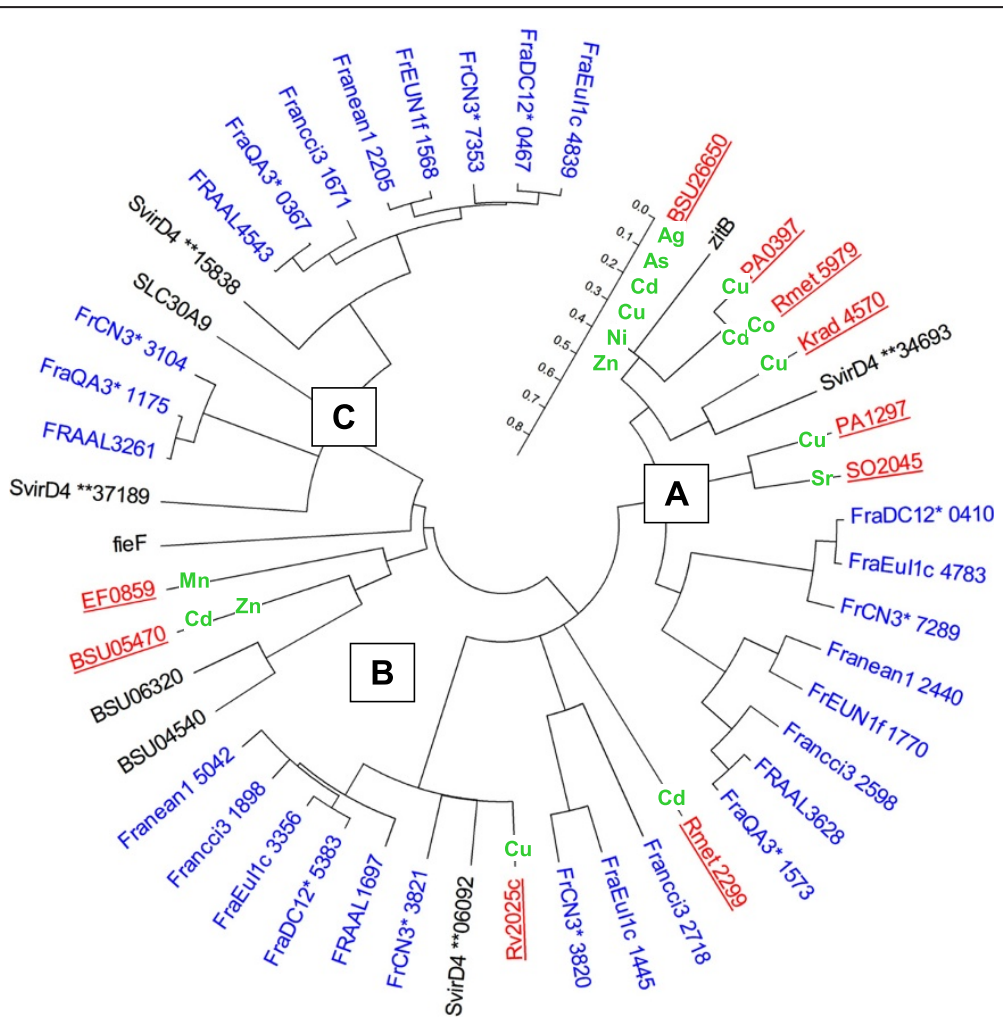

Figure 2 Phylogeny of cation diffusion facilitators in Frankia. Neighbor-joining tree of Frankia proteins containing the cation diffusion facilitator (CDF) domain (pfam01545). CDFs used for comparison include the characterized ZnT-9 from Homo sapiens (SLC30A9), iron (FieF) and zinc (ZitB) CDFs from E. coli K12-W3110, and CDFs up-regulated in the compiled array data (underlined) (see Additional file 1). CDFs of S. viridochromogenes and B. subtilis subtilis 168, which were used for specific metal resistance comparison in Richards et. al. 2002, were also included. Metals that are up-regulated-specific proteins are displayed on their branches. In locus tags: ${ }^{*}=\mathrm{DRAFT},{ }^{*}=0101000$. The following three types of CDF and identifying regular expression amino acid motifs are shown ("." indicates any single amino acid, and "*." indicates unspecified number of amino acids): A. CzCD:

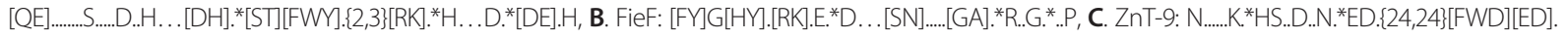


Nickel and oligopeptide $\mathrm{ABC}$ transporter subunits are highly homologous and multiple nickel/oligopeptide cassettes are frequently present in a genome [69]. Protein sequence alignments showed that oligopeptide (DppA) and nickel transporters of Escherichia coli and Bacillus subtilis are more closely related to each other than any of the Frankia homologs (data not shown), making the separation of these functions in Frankia impossible without experimentation. NikA/ DppA homologs are also heme binding, creating a relationship between iron and nickel transport, possibly due to NiFe cofactored enzymes (e.g. hydrogenase) [75]. The nickel-iron link may explain both the large number of NikA homologs, which were directly proportional to the number of bacterioferritins in their respective Frankia strains (Additional file 10 ), and the large number of iron and nickel co-factored proteins in Frankia (Tables 1).

Once inside the cell, chaperones, such as UreG and HypAB, bind and insert nickel into the appropriate protein (e.g. urease) [76]. Both of these chaperones were found in all of the Frankia genomes (Additional file 3). At elevated levels, nickel becomes toxic due to displacement of cognate metal cofactors in enzymes that facilitate electron transfers [77]. With B. subtilis, the cation diffusion facilitator $(\mathrm{CzcD})$ was more highly expressed with nickel exposure over that of any other cation (Additional file 1). Frankia strains, which are equally resistant to nickel as E. coli and B. subtilis [5], have ortho$\operatorname{logs}$ to $\mathrm{CzcD}_{\text {Bsub }}$ (Figure 2) and so may also use $\mathrm{CzcD}$ to export surplus nickel. Frankia sp. strain EAN1pec, EUN1f, and $\mathrm{CN} 3$ genomes contained a nickel permease that phylogenetically clusters with the nickel and cobalt efflux permease (RcnA) from E. coli rather than NhlF (Additional file 4). This transporter provides only a low-level of nickel resistance [78], but may have another function since all of the Frankia strains are similarly resistant to $\mathrm{Ni}^{2+}$.

Cobalt plays an important role as a cofactor for corrinoids, such as cobalamin (vitamin B12), and several other metalloenzymes including methionine synthase and bromoperoxidase [70]. The cobalt import cassette (CbiMNOQ) is an energy coupled factor (ECF)-type cobalt transporter involved in cobalamin formation [79]. Only Frankia EUN1f and EAN1pec genomes possessed CbiMNOQ. The other Frankia strains may be obtaining sufficient cobalt via the CbtA, CorA, or MgtE permeases (Table 2). These permeases allow passage of $\mathrm{Co}^{2+}$ and other divalent cations [61].

Cobalt toxicity is due to generation of reactive oxygen species and mis-incorporation into iron metalloproteins [70]. To guide correct insertion of cobalt into proteins, all of the Frankia genomes possessed both aerobic $(\mathrm{CobN})$ and anaerobic (CbiX) cobalt chaperones. While Frankia is not an anaerobe, it can lower cytoplasmic oxygen to protect the nitrogenase complex inside nitrogen-fixing vesicles surrounded by multiple layers of hopanoid lipids [80]. At least two copies of the cobalt exporter $(\operatorname{cor} C)$ gene were found in all of the Frankia genomes (Additional file 10). In several different bacteria, this transporter was up-regulated with a variety of di- and tri- valent metals (Additional file 1 ), and may function as the exporter counterpart to the general metal importer CorA.

\section{Copper homeostasis}

Bacterial cuproenzymes are typically involved in cellular redox cycling reactions, such as oxidation of carbon compounds (e.g. laccase, tyrosinase), electron transport (e.g. cyanins, cytochrome c), and reduction of inorganic oxides (e.g. nitrite reductase, superoxide dismutase) [81]. In Gram-negative bacteria, the use of copper is limited to either the periplasm or cytoplasmic membrane, and so there are few known copper-specific importers [71]. In Gram-positive bacteria, the absence of a periplasm for handling copper necessitated cytoplasmic involvement. This likely drove the evolution of a copper influx permease (YcnJ) and the more copper-resistant cellular thiols (e.g. mycothiol) $[82,83]$. The proposed process of copper homeostasis in Frankia is as follows: copper import via YcnJ [84], detoxification by metallothioneins (MrnA) [85], chaperoning of copper to cuproenzymes or exporters by CopZ [86], and exported by transporters such as CopA and CopCD [20,81]. Furthermore, three of Frankia strains (DC12, EuI1c, and CN3) are highly resistant to copper at MIC values of 2, 5, and $20 \mathrm{mM}$, respectively [5]. Studies on copper resistance are complicated due to the presence of multiple resistance mechanisms (CopZA, CopABCD operon, and the CusCBA) [85]. With Frankia, mechanisms for copper resistance were not obvious. Frankia genomes did not possess a CusCBA system, and all of them have at least one $\mathrm{Cu}^{2+}$-ATPase $(\operatorname{cop} A)$ and two $\operatorname{cop} C D$ genes (Table 2). Amino acid substitutions in copies of CopA and CopD are likely contributors to the high levels of copper resistance in the resistant Frankia strains (discussed below).

Bacterial P-type ATPases fall into two types: one exports copper and silver (EC:3.6.3.4), the other generally exports lead, zinc, and cadmium (EC:3.6.3.5) [20]. Protein sequence comparison with experimentally verified P-type ATPases indicated that 14 out of 15 Frankia ATPases were of the $\mathrm{Cu} / \mathrm{Ag}$-type (CopA) (Figure 3). CopA proteins are distinguished by the amino acid motif, CPxALGLATP, found in trans-membrane segment 6 , compared to the xPCALVxxTx motif of $\mathrm{Pb} / \mathrm{Cd} / \mathrm{Zn}$-type ATPases (Figure 3). Several Frankia genomes contained duplications of $\operatorname{cop} A$, but all $\operatorname{cop} A$ genes in copper sensitive strains were on a distinct phylogenetic branch (Additional file 5). Many CopA proteins function as a low rate copper efflux system for cytochrome c oxidase, rather than as a resistance 


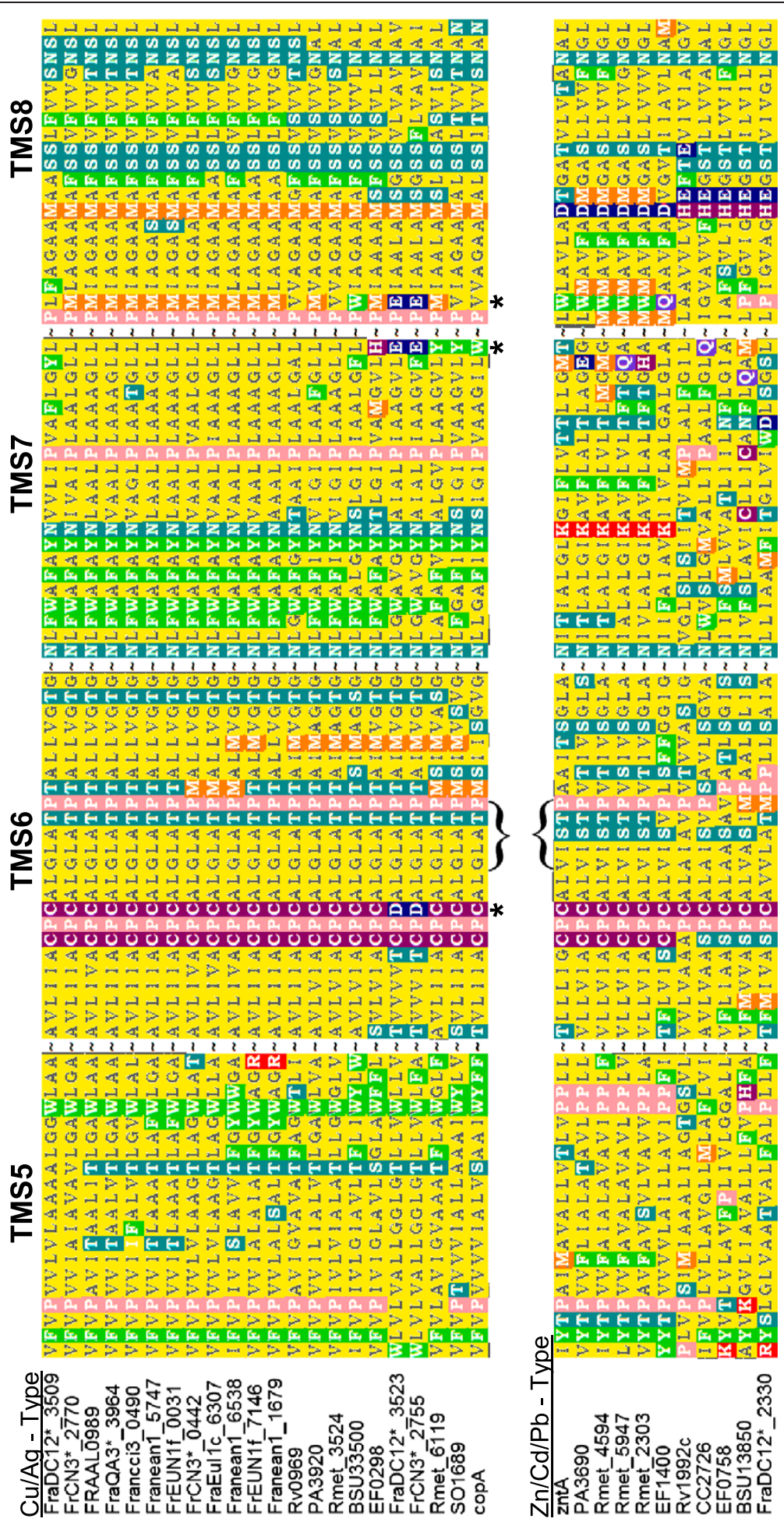

Figure 3 Protein alignment of transmembrane segments 5 thru 8 of $\mathrm{Cu} / \mathrm{Ag}$ or $\mathrm{Zn} / \mathrm{Cd} / \mathrm{Pb}$ - type $\mathrm{P}_{1 \mathrm{~B}}-\mathrm{ATPases}$ in Frankia. Transmembrane segments of Frankia heavy metal exporting ATPases (EC: 3.6.3.4 and 3.6.3.5) were aligned to identify amino acid changes that may alter metal specificity. Characterized ATPases from Escherichia coli K12-W3110 and those gene products that were up-regulated in the multiple array studies are included for comparison. Brackets indicate conserved amino acids that distinguish Cu/Ag - type from Zn/Cd/Pb - type ATPases. Asterisks indicate aspartate (D) and glutamate (E) amino acid residues in Frankia strains CN3 and DC12 that are potentially important for enhanced copper export. Amino acids are colored by characteristic: dark blue are negatively charged $(\mathrm{D} / \mathrm{E})$, purple are uncharged metal-binding $(\mathrm{C} / \mathrm{H})$, red are positively charged $(K / R)$, pink are cyclic $(\mathrm{P})$, orange are metal-binding and hydrophobic (M), yellow are hydrophobic (L/N/M/G/A), green are aromatic (F/W/M), light blue are polar (S/T/N/Q). 
mechanism [87]. Both heme and cytochrome c biosynthesis operons are located in the copA gene neighborhood of Frankia genomes (Additional file 8). It is possible that most Frankia CopA proteins function to provide copper to electron transport chain components, or to maintain low cytoplasmic copper levels during heme synthesis [84].

Two duplicate CopA proteins (FrCN3draft_2755 and FraDC12draft_3523) contained several amino acid substitutions with negatively charged residues (Asp and Glu) and had a His rich N-terminus (Figure 3). These proteins also grouped phylogenetically with well-characterized copper-resistance CopA transporters rather than other Frankia $\mathrm{Cu}^{2+}$-ATPases (Additional file 5). This evidence would suggest that these $\mathrm{Cu}^{2+}$-ATPases may function as copper resistance mechanisms for CN3 and DC12.

YcnJ, was found in each Frankia genome (Table 2), and consists of a fused CopC/CopD polypeptide that may function as a copper importer under copper limiting conditions [84]. Another copper transport system is the $\operatorname{cop} A B C D$ operon (copA here being a multi-copper oxidase not a $\mathrm{Cu}^{2+}$-ATPase), which has been implicated in both copper import and export $[81,88,89]$. CopC and CopD are considered a functional unit, with CopC binding copper, possibly for delivery to the copper permease CopD [81]. All Frankia strains have both copper importing YcnJ and copper importing/exporting CopCD systems (Additional file 6). In Frankia, CopD is a polypeptide with an attached cytochrome $\mathrm{C}$ oxidase (Caa3) domain. $\mathrm{CopC}$ and SenC may work in tandem with this CopD-Caa3 protein to delivery copper to membrane bound cytochromes [90].

Both YcnJ and CopCD transporters tend to contain more charged and metal-binding amino acids in the resistant Frankia strains (not shown) and they form separate groups phylogenetically (Additional file 6). Frankia sp. strain EuI1c also has a third CopD (FraEuI1c_1869) which lacks the Caa3 domain, has increased metal binding amino acids, and groups phylogenetically with the two CopD proteins from the highly copper resistant $C$. metallidurans (Additional file 6). These two copD genes (Rmet_5668 and Rmet_6115) are up-regulated either with copper or with copper and other divalent cations (respectively) (Additional file 1).

The transcriptional response to copper was examined in Frankia sp. strain Eul1c [91]. All of the predicted copper transporters (CopD and YcnJ) and copper binding proteins (CopC and CopZ) are up-regulated in the presence of elevate copper levels [91]. In summary, duplication and modification of amino acids in copper transporters, CopD for strain EuI1c and CopA for strains DC12 and CN3, may explain the high resistance in these Frankia strains. Interestingly, these three copper-resistant strains are also atypical (non-nitrogen fixing) Frankia strains, although there is no clear link between nitrogen fixation and copper sensitivity.

\section{Molybdenum homeostasis}

Molybdenum is found as part of an iron-sulfur cofactor in nitrogenase or combined with a tricyclic pterin forming the molybdenum cofactor (MoCo) [72]. MoCo oxidoreductases are nearly ubiquitous in life, and include many important enzymes classes including several dehydrogenases and ferredoxin oxidoreductases [92]. Molybdenum enters the cell through the high affinity $A B C$ cassette (ModABC) or through low affinity sulfate permeases, SulT and SulP, due to its chemical similarity to sulfate [73]. All of the Frankia genomes have the ModABC cassette and several copies of SulP for high and low-affinity molybdate transport (Table 2). The molybdate chaperone (ModG) was only found in the genomes of nitrogen-fixing Frankia strains (Table 2), suggesting ModG is involved in the synthesis of the iron-molybdate nitrogenase cofactor [72]. The non-nitrogen-fixing Frankia genomes CN3, DC12, and EuI1c contain a sulfate export protein (TauZ). Since molybdate will enter through general sulfate importers, it is possible that TauZ could function to export surplus molybdate. All nitrogen-fixing Frankia strains lack TauZ, possibly to retain their molybdenum reserves.

\section{Selenium homeostasis}

Selenium, in the form of selenocysteine or selenomethionine, is found in several stress proteins including glutathione peroxidase, alkyl hydroperoxidase, and multiple disulfide reductases [93]. The deprotonated electrons of selenium cofactors make the selenoproteins reduction-oxidation reactive, explaining why many identified selenoproteins are involved in thiol and oxidative stress resistance [93]. Since selenite generates these stresses in the cell, the stress-related selenoproteins may function in both detoxification and removal of free selenite ions from the cytoplasm [94]. Only $20 \%$ of sequenced bacteria are known to contain selenoproteins [47]. All of the Frankia genomes contained selenoproteins (Table 1).

As a sulfur analogue, selenium oxyanions enter cells through sulfate transporters such as SulP and CysPUWA, but selenite competitively inhibits the sulfate uptake through SulP [73]. In this study, four Frankia strains (DC12, EUN1f, EuI1c, and $\mathrm{CN} 3$ ) have elevated levels of selenite resistance (up to $3.5 \mathrm{mM}$ ) compared to E. coli $\mathrm{K} 12(0.5 \mathrm{mM})$ [5]. Only the genomes from these selenite-resistant Frankia strains contained both the SulP and CysPUWA sulfate permeases genes (Table 2), which are likely to prevent sulfur starvation in the presence of selenite.

Once inside the cell, selenite is reduced to inert insoluble elemental selenium, which has red color [95]. A red precipitate is formed by the selenite resistant Frankia strains CN3, EuI1c, EUN1f and DC12 implying selenite reduction [5]. Recently, selenite reduction and selenium nanosphere production was verified in Frankia strain EuI1c [96]. Small thiol-containing molecules, like glutathione, 
reduce selenite to seleno-diglutathione, which is further reduced to selenopersulfide by glutathione reductase [95]. Only Frankia EuI1c, EAN, and CN3 genomes contained glutathione synthase (GSH) (Table 2). However, all of the Frankia genomes contained synthase proteins for small thiols like mycothiol (MSH) (Table 2), which may substitute for glutathione for metal resistance [97]. Selenium is also reduced enzymatically either through thioredoxin and its reductase (TrxA and B) or nitrate/nitrite reductases [98]. These reductases are found in all Frankia genomes, likely to supply the cell with selenopersulfide. The selenopersulfide is either integrated into proteins via selenocysteine or spontaneously dismutates into elemental selenium [95]. The Frankia $\mathrm{CN} 3$ genome has a second type of nitrate reductase (NasC) that was associated with nitrite reductases (NirBD), and may contribute to the greater levels of selenite resistance in Frankia strain CN3 (Additional file 10).

Selenium-resistant strains also contained sulfite oxidase genes (FraEuI1c_6626, FrCN3DRAFT_7646, FrEUN1f_7579). Sulfite oxidase (SorA) converts selenite to the less toxic selenate $[98,99]$. In summary, Frankia selenite resistance is likely due to alternate sulfate transporters (CysPUWA) that prevents sulfur starvation. Additional selenite resistance may result from oxidation of selenite to the less toxic selenate using SorA, or from selenite reduction. The selenite reduction observed in resistant strains could occur through several mechanism including mycothiol, TrxAB, YedY, or NasC/NirBD.

\section{Part 2: Toxic metals}

\section{Arsenate resistance}

Being structurally analogous to phosphate, arsenate enters the cells through phosphate uptake transporters and acts as a metabolic poison [100]. Arsenate resistance involved the reduction of arsenate to arsenite, which is transported out of the cell [101]. Arsenate reduction to arsenite occurs by either the glutaredoxin-dependent ArsC (KO:K00537) or a thioredoxin-dependent phosphotyrosine-phosphatase (PTPase) termed ArsC2 (KO:K03741) [102]. These reductases are typically found in an ars operon with an ars $R$ regulator and one of several types of arsenite transporters (ars $A B$, arsB, acr3, or aqpS) [100]. Arsenate reduction by Frankia likely involves ArsC2 and mycothiol, which substitutes for glutathione in the arsenate reduction process [102]. Glyoxalase I isomerizes hemithioacetal adducts (glutathione recycling), is responsive to various heavy metals, and is often found associated with ars operons in bacteria [103-105]. A cadmium-inducible glyoxyalase I (CadI) was also found within all of the potential Frankia arsenate resistance operons (data not shown). This evidence suggests CadI may assist in reducing glutathione/mycothiol-arsenical complexes.

Several Frankia strains are significantly more resistant to arsenate than E. coli ( $>50 \mathrm{mM}$ vs. $10 \mathrm{mM}$ ), but not to arsenite $(0.1 \mathrm{mM}$ vs. $3 \mathrm{mM})$ [5]. A similar pattern of arsenate resistance and arsenite sensitivity was observed with Sinorhizobium meliloti, which has a novel pathway for arsenate resistance [106]. In S. meliloti, ArsC reduces arsenate to arsenite which is exported out of the cell via an aquaglyceroporin (AqpS) [106]. Only one (SMc02648) of the three AqpS homologs in S. meliloti is involved in arsenite export [106]. Most Frankia genomes contained at least two aqpS genes (Table 2). Phylogenetic analysis placed Frankia AqpS proteins on two of three distinct branches of aquaglyceroporins (Additional file 7). One branch of Frankia Aqps proteins was orthologous to SMc02648. The gene neighborhood of these Frankia aqpS genes contained the arsR, arsC2 and cadI genes (not shown). Frankia EuI1c genome contained 2 copies of aqpS genes, but was 10 -fold more sensitive to arsenate than other Frankia strain. The duplicated aqpS gene (FraEuI1c_6606) was missing the last two transmembrane domains, and had more positively-charged arginine residues (40 vs 9) on the long cytoplasmic c-terminal stretch. Possible explanations for this strain increased arsenate sensitivity is that this protein may form only a dysfunctional channel, or retain arsenic oxyanions on the positively charged cytoplasmic domains.

A second branch of the aquaporin (AqpZ) proteins contains two members that were up-regulated with heavy metals (Additional file 7). These AqpZ proteins were nearly identical to AqpS except they lacked the long cytoplasmic c-terminus (data not shown). The third branch of this phylogenetic tree contained homologs that were related to the glycerol uptake facilitators (GlpF), which are also known for arsenite-importing in both eukaryotes and prokaryotes [100]. No $g l p F$ genes were found in any of the Frankia genomes. Another arsenite transporter (ACR3), an arsenite sodium symporter, was identified in a few Frankia genomes (Table 2), but its presence did not correlate to the levels of arsenate or arsenite resistance.

\section{Chromate resistance}

Chromate enters the cell through sulfate permeases, and is a potent inducer of oxidative stress and DNA repair mechanisms [107]. Chromate resistance involves export by the chromate permease (ChrA) followed by reduction either by $\mathrm{ChrB}$ or by a number of other proteins (nitrite reductase, quinone oxidoreductases, cytochromes, glutathione, etc.) [107,108]. Most Frankia strains are more resistant to chromate than E. coli, B. subtilis, and $C$. metallidurans [5]. The presence or absence of ChrA in the Frankia genomes did not correlate to their levels of resistance. Other known chromate-resistance determinants [108-110] were either not present in the Frankia genomes or did not correlate to chromate resistance levels.

By looking at genes present only in more chromate resistant (MIC $>1 \mathrm{mM}$ ) Frankia strains, 2 candidate chromate resistance genes were identified. One was a 
metallo- $\beta$-lactamase, which is unlikely to be involved in chromate resistance. The other gene coded for a possible metallothionein, which contained 3 or 4 CXXC motifs interspersed with multiple histidines (Additional file 9). Metallothioneins are involved in chromate binding and reduction through thioester bond formation [111], and are found in association with the ChrA transporter in related actinobacteria [112]. Therefore, it is possible that this metallothionein contributes to chromate resistance in Frankia.

\section{Lead resistance}

Lead enters cells through $\mathrm{Fe}^{2+}$ and $\mathrm{Ca}^{2+}$ transporters, and exerts its toxicity by displacing these cations at their binding sites in metalloproteins [113]. The most well-characterized lead resistance mechanism occurs in C. metallidurans. This mechanism involves lead export through the $\mathrm{Zn}^{2+}$-type ATPase (PbrA), followed by precipitation on the cytoplasmic membrane through the combined action of a PAP-2 phosphatase and signal peptidase ( $\mathrm{PbrB}$ and $\mathrm{PbrC}$, respectively) [114]. Lead easily forms stable lead-phosphate precipitates. Several gram-positive and gram-negative bacteria exploit this property to detoxify lead as intra- or extracellular precipitates [115].

All of the Frankia strains are highly lead resistant with up to 8-fold higher levels compared to C. metallidurans and at least 2-fold greater than S. viridochromogenes levels [5]. Frankia was also able to bind significant amounts of lead as a precipitate [116]. In a genome-wide array study of $C$. metallidurans under lead stress, the most lead-responsive gene was the $\operatorname{cop} A$-like gene (Rmet_3524) [6]. The lead resistance genes, pbrABCDT, are up-regulated primarily with zinc and cadmium stress with only pbrA being up-regulated with lead stress [6]. All of the Frankia genomes contained $\operatorname{cop} A$ genes and these gene products were significantly divergent from the other characterized CopA proteins (Additional file 5). One possibility is that the Frankia $\mathrm{Cu}^{2+}$-ATPases also export other metals like $\mathrm{Pb}^{2+}$. Phosphate utilization (e.g. polyphosphate phosphatase) and cell surface modification proteins (e.g. UDP-glucose 4-epimerase) were located within the highly conserved gene neighborhood of the Frankia copA genes (Additional file 8). These proteins are known to play a role in the surface binding of $\mathrm{Pb}^{2+}$ [117].

In a Bacillus isolate which lacked the $p b r A$ and $p b r T$ genes, lead was exported by alternate transporters, but is still bound extracellularly [118]. Among the genes that are up-regulated with lead stress, there are 3 paralogous operons containing the genes for undecaprenyl phosphatase (UppP) and DUF347 protein (Additional file 1). Although UppP does not necessarily cause metal resistance, it may help to stop the futile metal import-export cycle by precipitating metals on the cell surface [119]. The DUF347 protein is 6 trans-membrane-segment protein that may work in conjunction with the co-expressed
UppP as another metal export-precipitation system. In Thalassiosira pseudonana, DUF347 is the most highly up-regulated gene that was divalent metal-specific [120] supporting this hypothesis. All of the Frankia genomes contained at least one copy of DUF347 and multiple copies of UppP (Table 2). In contrast, only 3 of the 18 non-Frankia bacterial genomes contained a DUF347 or multiple UppP orthologs (Additional file 10). The presence of DUF347 or multiple UppP orthologs could explain the high lead resistance levels for these Frankia strains.

\section{Tellurite resistance}

Tellurite is considered a biologically useless metalloid. Due to its induction of oxidative stress in bacteria, tellurite is toxic at micromolar levels [121]. Tellurite enters bacterial cells through either the phosphate transporter (PitA) or nitrate transporters [122,123]. Similar to selenite, tellurite is detoxified through a reduction mechanism by nitrate/nitrate reductases and small cellular thiols like glutathione, leaving an insoluble black precipitate [121,124]. Additionally, there are specific tellurite resistance genes including telAB, ter $A B C D E Z$, and teh $A B$, but little information exists on their exact functions [121]. While tellurite resistance levels have not been established for Frankia, there were several factors that suggested potential tellurite resistance. Many Frankia strains were also resistant to other metal oxyanions like selenite and arsenate. Secondly, all of the Frankia genomes had a full set of $\operatorname{ter} A B C D E Z$ genes and nitrite reductases (NirBD). Bacteria having terABCDEZ operons are frequently resistant up to $4 \mathrm{mM}$ tellurite [125]. Frankia $\mathrm{CcI} 3$ and $\mathrm{CN} 3$ genomes also had nitrate reductase (NasC) gene, which could be used for selenite or tellurite reduction [121]. To test our hypothesis and to distinguish between tellurite and selenite resistance, Frankia strain CcI3, which is selenite-sensitive, was grown on tellurite agar. Frankia strain CcI3 was able to grow in the presence of tellurite and produced black elemental tellurium in medium containing up to $3 \mathrm{mM} \mathrm{TeO}_{3}$ (Additional file 19).

\section{Metal regulation}

The MerR family contains several types of self-regulating transcriptional activators of genes involved in copper/silver resistance (CueR), gold (GolS), mercury resistance (MerR), zinc (ZntR), cadmium (CadR), lead (PbrR), cobalt (CoaR), oxidative stress (SoxR), nitrogen metabolism (GlnR), biofilm formation (MlrA), and heat shock (DnaK) [126-128]. There are between 9 and 20 MerR proteins in Frankia genomes (Additional file 10), which phylogenically cluster into ten groups (Additional file 20). Four of these nine groups could be metal responsive based on a conserved amino acid motif (Additional file 10) derived from sequence alignments of metal induced MerR genes from compiled gene arrays (Additional file 1). None of the metal-related merR genes are located in operons with 
metal resistance proteins, so are likely regulating acting in trans.

The second largest family of metal regulators in Frankia include members of ArsR/SmtB-family. Originally characterized as a repressor of the arsenic responsive ars operon, members of this family can respond to a variety of metals (nickel, zinc, copper, cadmium, lead), causing de-repression of regulatory targets [129]. In Frankia, ArsR proteins phylogenetically cluster into 5 groups. One groups is part of the potential arsenic resistance operon (Additional file 21). There is also a large group of ArsR-like proteins in a potential operon with activator of HSP90 ATPases (AHSA1), though a direct link between ArsR and AHSA1 expression has not been elucidated. A third group shows sequence similarity to the nickel sensor from M. tuberculosis (NmtR), though retain no synteny or proximity to metal transporters. A small group of ArsR proteins are orthologous with the cadmium and lead responsive CmtR of M. tuberculosis and nickel responsive SrnR of Streptomyces griseus [130,131]. Members of this group of Frankia ArsR proteins are in a possible operon with the metal exporter $\mathrm{CzcD}$ (Additional file 21). The last group shows no homology to any characterized ArsR family proteins and are not proximal to other metal related genes.

Another family of transcriptional repressors includes orthologs of the copper-sensitive operon repressor (CsoR) [132]. These regulators are primarily responsive to either copper (CsoR, RicR) or to nickel and cobalt (DmeR, RcnR), though other metals have been demonstrated to induce gene derepression by these regulators [132-136]. Several CsoR proteins were demonstrated to regulate metal exporters such as $\mathrm{Cu}$-ATPase (CopA) [133]. Frankia contains orthologs to CsoR, RicR, and an uncharacterized CsoR-like protein (Additional file 22). The Frankia sp. strain CN3 CsoR ortholog (FrCN3DRAFT_2771) is directly downstream of CopA, maintaining synteny with characterized CsoR proteins (Additional file 22).

The other Frankia strains contain orthologs to Ric $\mathrm{R}_{\text {Mtub }}$ (Additional file 22), which is responsive to copper, iron, and zinc [134]. A branch of Frankia CsoR-like proteins (Franean1_3360, FrEUN1f_0873, FrCN3DRAFT_5236) cluster with an uncharacterized regulator (Rv1766) and to a lesser extent the copper and nickel responsive $\mathrm{CsoR}_{\text {Mtub }}$ (Additional file 22). These CsoR-like proteins have the amino acid motif (R..R...Q.........[ED]... [DE]C.....Q. $\{22\}[\mathrm{HC}])$ of nickel regulators RcnR/DmeR, which lacks the tyrosine (Y) and H...C section of the CsoR/ RicR motif (R.\{13\}M.....YC.D."H...C). Only the Frankia genomes containing an ortholog to nickel-exporting RenA (Additional file 10) have orthologs of the uncharacterized CsoR-like protein, further suggesting that they may be involved in nickel regulation (Additional file 22).

The iron transport repressor (Fur) binds a variety of essential divalent metals including iron (Fur), zinc (Zur), nickel (Nur), manganese (Mur), or cobalt (Co-Fur) the combination of which determines the level of Fur transcription [137]. Bacteria contain an additional layer of Fur-family proteins (eg. PerR) which also bind metals and regulate the transcription of Fur [137]. Orthologs of Fur and Nur have been previously examined in Frankia which retain a high level of protein sequence conservation to characterized proteins $[138,139]$. In Frankia, Fur is located in an operon with either KatA or KatG catalases (Additional file 23), which rely on iron (heme) to function $[140,141]$. There are two phylogenetic groups of Frankia Nur proteins (Additional file 23). For cluster I Frankia nur is located adjacent to a metallopeptidase $(g c p)$ and the nickel chaperone ureG. In cluster III and IV Frankia genomes, nur is upstream of an ironsulphur cluster repair protein (YgfZ). The characterized S. coelicolor Nur ortholog is also co-located with YgfZ and has been demonstrated to regulate nickel import genes (nikABCDE) and oxidative stress (sodF) [139].

Another Fur paralog (Zur) regulates zinc importers, and is itself regulated by ArsR as demonstrated in $M$. tuberculosis [142]. ArsR is zinc responsive and may work with Zur to regulate intracellular zinc through repression and derepression of the cation transporter CzcD [143]. While all Frankia genomes contained a Zur regional to the zinc importer ZntABC, Frankia sp. strain DC12 has a second Zur in an operon with ArsR (Additional file 23). The remaining Fur protein in Frankia (PerR) is in operon with rubrerythrin, which binds iron and zinc and is involved in oxidative stress response [144]. The Frankia genomes contain a second type of iron regulatory protein, diptheria toxin repressor (DtxR) (Additional file 10), which regulate several iron related proteins including siderophores and iron storage proteins [145]. The Frankia DtxR proteins are distinguished from the closely related manganese regulator (MntR) by the conservation of four amino acid residues previously identified as iron binding [146].

\section{Conclusions}

Frankia has successfully adapted to a challenging habitat: an acidic rhizosphere full of secondary metabolites, plant phenolics, and solubilized metals. To accomplish this feat, Frankia has a full complement of proteins that use all major beneficial metals. Frankia metal resistance patterns appear to be unique to each strain. The high levels of copper resistance appears to be due to duplicated $\operatorname{copD}$ genes in Frankia sp. strain EuIlc and unusual $\operatorname{copA}$ genes in strains $\mathrm{CN} 3$ and DC12. Selenite resistance involves an alternate sulfur importer (CysPUWA) working with reductases to produce elemental selenium. Nickel, cobalt, zinc, and cadmium resistance are likely the result of a combination of CDF proteins. Lead appears to be exported via $\mathrm{Cu}^{2+}$ - ATPases or DUF347, and precipitated as a bound metal phosphate similar to other bacterial 
species. Frankia arsenate resistance appears to be achieved through a novel mechanism utilizing an aquaporin (AqpS) that was discovered in nitrogen-fixing $S$. meliloti. The ter $A B C D E Z$ genes and various reductases provide Frankia CcI3 (and possibly other Frankia strains) with tellurite resistance. Frankia has achieved similar levels of metal and metalloid resistance as bacteria from highly metal-contaminated sites. The potential for use of Frankia-actinorhizal symbiosis in bioremediation efforts makes further research into expression of these genes worthwhile.

\section{Methods}

\section{Gene identification in Frankia}

An initial list of genes involved in Frankia metal homeostasis was created using a combination of comparative analyses, motif searches, PERL algorithms, and microarray data (Additional file 24). Comparative analysis of Frankia and other genomes was performed primarily using the Integrated Microbial Genome (IMG) database [147]. Metal homeostasis genes identified in the literature that lacked locus tags or gene accession numbers were identified through the UniProt database [148]. Orthologs of genes from functionally characterized proteins of other microorganisms were identified in Frankia using the embedded BLASTp software on IMG. Proteins with a minimum of $30 \%$ identity and e-values $<10^{-20}$ were considered orthologs.

\section{Low scoring and hypothetical proteins}

The large phylogenetic distance between Frankia and model organisms, such as E. coli and B. subtilis, meant many of the closest metal transport homologs in Frankia had less than $30 \%$ identity and e-values of $>10^{-20}$. These low-scoring genes, as well as all hypothetical proteins were: 1. examined for conservation of domains from other databases including protein families (Pfam) [149], gene ontology [150], and cluster of orthologous groups (COG) [151], 2. individually analyzed for conserved metal binding residues as compared to characterized metal resistance genes, 3 . visually checked for neighborhood synteny and clustering with other metal homeostasis genes using native IMG tools [147].

\section{Gene array meta-analysis}

Genes from 16 different published whole genome array studies involving bacterial response to heavy metals were analyzed as follows. Any potential metal homeostasis proteins that were significantly (based on originating paper cut-off) up-regulated were included for analysis. Genes were assigned an IMG identifier by downloading the genome data from IMG for each organism and matching genes from the arrays to the IMG data using Excel tools. The genes were uploaded to IMG and the various information about the genes (symbol, COG numbers, protein domains...etc) were obtained and exported. The expression data were matched to the downloaded IMG gene information and this collective data was combined and analyzed in Excel (Additional file 1).

To normalize gene expression between studies, the genes of each study were ranked by dividing the fold change of each gene by the maximum fold change in that study. Thus, the gene with the maximum response has a value of 1 and the remaining genes are a fraction of the maximal response (Additional file 1). Up-regulated genes in multiple different species/array studies were selected for analysis. BLASTp searches were done using IMG to identify orthologs of these genes in the Frankia genomes.

\section{Assessment of metal binding potential}

Using the regular expression search function on IMG and in-house PERL algorithms, the Frankia genome were searched for proteins containing either conserved metal binding motifs obtained from the literature or high metalbinding potential as previously described [112]. Since each genome has a unique amino acid distribution, all proteins in each genome were scaled by \% of each individual amino acid. Proteins in the top $1 \%$ highest cysteine or histidine were considered potentially metal binding and examined for other metal homeostasis factors, including: neighboring metal-related genes, presence/absence in metal resistant strains, orthology to genes up-regulated with metal in array studies.

\section{Phylogenic tests of relatedness}

To distinguish highly similar mechanisms or metal specificity, phylogenetic trees were constructed with proteins from Frankia and organisms that were either: 1. from metal homeostasis literature, 2. from past studies involving Frankia metal resistance, and/or 3. from the compiled gene array studies. General comparative organisms for gene identification can be found in Additional file 10 and include either organisms used in the Richards et. al. 2002 analysis of Frankia metal resistance or organisms with model metal homeostasis systems in 4 major categories: actinobacteria, Gram positive and negative bacteria, and eukaryotes (to demonstrate genetic distance). Alignments were created using ClustalW in BioEdit [152], and neighbor-joining trees with 1000 bootstraps were constructed using MEGA software [153]. Functionality or metal specificity was tentatively assigned based on grouping with experimentally characterized proteins from the literature.

\section{Ethics}

This study did not involve humans, animals or plants in any manner. 


\section{Additional files}

Additional file 1: Compiled data from global gene expression studies in response to metals. Genes from 16 global gene expression studies were identified in the IMG database. Protein data was downloaded, matched to expression levels, and organized in Excel. To be able to compare across studies, the gene with the maximal expression in each study was set to 1 with all other genes normalized to that gene. COG and Pfam counts were also calculated and genes with high COG or Pfam counts that were also found in multiple organisms per metal were used to: 1. identify novel resistance mechanisms, 2 . confirm likeliness of identified resistance mechanisms in Frankia, and 3. determine metal specificity of identified mechanisms (if any).

\section{Additional file 2: Phylogeny of Frankia iron-siderophore ABC} cassettes. Un-rooted neighbor-joining tree of iron ABC permeases in Frankia, those characterized in E. coli, and those up-regulated with heavy metals (underlined) (Additional file 1). Identifying COG domains found in the displayed proteins are shown on their respective branches.

\section{Additional file 3: Phylogeny of Frankia metal chaperones} containing COG0523 domains. Circular neighbor-joining tree of Frankia proteins identified by BLASTp as orthologs of experimentally characterized (underlined) members of COG0523 family metal chaperones. Orthologs from metal resistant C. metallidurans CH34, Streptomyces viridochromogenes DSM 40736, Bacillus subtilis subtilis 168, Escherichia coli K12- W3110, and Helicobacter pylori B8 are shown for comparison. Characteristically defining domains for nickel cofactored HypB (KO:K04652) and UreG (KO:K03189), and the cobalt cofactored CobW (KOG2743) are shown on their associated branches.

Additional file 4: Nickel import vs export permeases. Neighborjoining tree of Frankia NixA-family permeases similar to either A. the nickel exporting RcnA (COG2215) or B. the nickel importing NhIF (KO:K07241). Proteins containing either domain that were up-regulated in the compiled array studies were also included. E. coli homolog to RcnA is YohM (Missing locus_tag).

Additional file 5: Phylogeny of Frankia $\mathrm{Cu}^{2+}$-ATPase proteins. Neighbor-joining tree of ClustalW aligned CopA proteins sequences from Frankia, E. coli, S. viridochromogenes and all $\mathrm{Zn}^{2+}$ - or $\mathrm{Cu}^{2+}$ - type ATPases up-regulated in the compiled array studies (underlined). Frankia CopA proteins (B) form a distinct group from characterized CopA proteins (A) in other bacterial species. The exceptions (C) are FrCN3DRAFT_2755 and FraDC12DRAFT 3523 which are highly homologous to the predicted copper resistance gene CopF of Cupravideous metallidurans (Rmet_6119). Of the Frankia genomes analyzed, only Frankia sp. strain DC12 has a ZntA type ATPase (D) though both CopA and ZntA proteins are up-regulated with a variety of metals (shown on their respective branches). E. coli K-12 W3110 CopA and ZntA is indicated with its gene name in black, all others are locus tags. ${ }^{*}=$ DRAFT, ${ }^{* *}=0101000$.

\section{Additional file 6: Phylogeny of Frankia CopC and CopD proteins.} Neighbor-joining tree of ClustalW aligned CopC and CopD protein sequences from Frankia and comparative organisms used in Richards et. al. 2002. Genes up-regulated with metals in compiled gene array studies are underlined. Identifying Pfam domains for each group of proteins was also included to show characteristics of Frankia CopCD proteins.

\section{$*$ DRAFT, ${ }^{* *}=0101000$}

\section{Additional file 7: Phylogeny of Frankia arsenic transport} permeases. Neighbor-joining tree of ClustalW aligned major intrinsic protein (MIP) domain (pfam00230) containing protein sequences from Frankia, from compiled gene arrays (underlined), and from several experimentally characterized genes. The novel arsenite exporting aquaporin from Sinorhizobium meliloti is in bold. Frankia sp. strain Eul1c contains a unique MIP (A) which may contribute to its sensitivity to arsenate. ${ }^{*}=$ DRAFT, ${ }^{* *}=0101000$.

Additional file 8: Gene neighborhood synteny of Frankia-type $\mathrm{Cu}^{2+}$-ATPases. The region contains genes for electron transport chain components [heme B, cytochrome $\mathrm{C}$, ubiquinone $(\mathrm{CoQ})$ /menaquinone (VitK)] and copper sequestration to the cell surface [phosphate metabolism and cell surface modification genes]. Association of CopA with this region suggests a dual purpose of decreasing heme disruption by cytoplasmic copper and delivering copper to the ETC complex IV. CopA in Frankia strains EAN, EUN, and CopZA in DC12 have been transposed to a different region in these genomes.

Additional file 9: Protein alignment of a potential metallothionein involved in chromate resistance. ClustalW alignment of a metallothionein found only in the chromate resistant bacterial strains based Richards et. al. 2002. Brackets indicate potential metal binding motifs. Amino acids are colored by characteristic: dark blue are negatively charged $(\mathrm{D} / \mathrm{E})$, purple are uncharged metal-binding $(\mathrm{C} / \mathrm{H})$, red are positively charged $(K / R)$, pink are cyclic $(P)$, orange are metal-binding and hydrophobic $(\mathrm{M})$, yellow are hydrophobic (L/IN/M/G/A), green are aromatic (F/N/Y), light blue are polar (S/T/N/Q).

Additional file 10: Summary of experimental gene data and evidence table. Literature summary, array data summary, and metal binding motifs used to identify metal resistance mechanisms in Frankia. My symbol assigned to a Frankia protein is based on either the phylogenetically closest or most well characterized protein ortholog. An identifying domain to distinguish closely related mechanisms, as well as some of the conserved amino acid motifs, was set using combined blast and phylogeny in the IMG site and related databases. Colorized gene counts from all array and comparative [5] organisms along with a few well characterized organisms including Helicobacter pylori, Streptomyces coelicolor, Staphylococcus aureus, and Saccharomyces cerevisiae are included for visual comparison to evidence.

Additional file 11: Frankia sp. strain $\mathrm{Ccl} 3$ metal homeostasis mechanisms. Schematic diagram of known and putative metal homeostasis systems in Frankia Ccl3. Loci containing identifying domains (see Additional file 10) for metal ion uptake transporters, chaperones, modification enzymes, efflux transporters, and surface binding protein and efflux systems are shown (left to right) with arrows to indicate the flow of metals through the cell. Information at the bottom indicates whether the strain is symbiotic with host plants $\left(\mathrm{Sym}^{+/-}\right)$, is a diazotroph $\left(\mathrm{N}_{2}-\mathrm{fix}^{+/-}\right)$, and whether the strain is resistant ( $r$ ) or sensitive ( $\mathrm{s}$ ) to a particular metal.

Additional file 12: Frankia sp. strain QA3 metal homeostasis mechanisms. Schematic diagram of known and putative metal homeostasis systems in Frankia sp. strain QA3. Loci containing identifying domains (see Additional file 10) for metal ion uptake transporters, chaperones, modification enzymes, efflux transporters, and surface binding protein and efflux systems are shown (left to right) with arrows to indicate the flow of metals through the cell. Information at the bottom indicates whether the strain is symbiotic with host plants $\left(\mathrm{Sym}^{+/}\right)$, is a diazotroph $\left(\mathrm{N}_{2}-\mathrm{fix}^{+/}\right)$, and whether the strain is resistant ( $\mathrm{r}$ ) or sensitive (s) to a particular metal. * ${ }^{*}$ DRAFT.

Additional file 13: Frankia alni ACN14a metal homeostasis mechanisms. Schematic diagram of known and putative metal homeostasis systems in Frankia alni ACN14a. Loci containing identifying domains (see Additional file 10) for metal ion uptake transporters, chaperones, modification enzymes, efflux transporters, and surface binding protein and efflux systems are shown (left to right) with arrows to indicate the flow of metals through the cell. Information at the bottom indicates whether the strain is symbiotic with host plants $\left(S y m^{+/}\right)$, is a diazotroph $\left(\mathrm{N}_{2}-\mathrm{fix}^{+/-}\right)$, and whether the strain is resistant (r) or sensitive (s) to a particular metal.

Additional file 14: Frankia sp. strain EUN1f metal homeostasis mechanisms. Schematic diagram of known and putative metal homeostasis systems in Frankia sp. strain EUN. Loci containing identifying domains (see Additional file 10) for metal ion uptake transporters, chaperones, modification enzymes, efflux transporters, and surface binding protein and efflux systems are shown (left to right) with arrows to indicate the flow of metals through the cell. Information at the bottom indicates whether the strain is symbiotic with host plants $\left(S y m^{+/}\right)$, is a diazotroph $\left(\mathrm{N}_{2}-\mathrm{fix}^{+/-}\right)$, and whether the strain is resistant (r) or sensitive (s) to a particular metal.

Additional file 15: Frankia sp. strain EAN1pec metal homeostasis mechanisms. Schematic diagram of known and putative metal homeostasis systems in Frankia sp. strain EAN1pec. Loci containing identifying domains (see Additional file 10) for metal ion uptake transporters, chaperones, modification enzymes, efflux transporters, and surface binding protein and efflux systems are shown (left to right) with 
arrows to indicate the flow of metals through the cell. Information at the bottom indicates whether the strain is symbiotic with host plants $\left(\mathrm{Sym}^{+-}\right)$, is a diazotroph $\left(\mathrm{N}_{2}-\mathrm{fix}{ }^{+-}\right)$, and whether the strain is resistant ( $\mathrm{r}$ ) or sensitive (s) to a particular metal.

\section{Additional file 16: Frankia sp. strain Eul1c metal homeostasis} mechanisms. Schematic diagram of known and putative metal homeostasis systems in Frankia sp. strain Eul1c. Loci containing identifying domains (see Additional file 10) for metal ion uptake transporters, chaperones, modification enzymes, efflux transporters, and surface binding protein and efflux systems are shown (left to right) with arrows to indicate the flow of metals through the cell. Information at the bottom indicates whether the strain is symbiotic with host plants $\left(\mathrm{Sym}^{+/}\right)$, is a diazotroph $\left(\mathrm{N}_{2}-\mathrm{fix} \mathrm{ix}^{+/}\right)$, and whether the strain is resistant (r) or sensitive (s) to a particular metal.

Additional file 17: Frankia sp. strain CN3 metal homeostasis mechanisms. Schematic diagram of known and putative metal homeostasis systems in Frankia sp. strain CN3. Loci containing identifying domains (see Additional file 10) for metal ion uptake transporters, chaperones, modification enzymes, efflux transporters, and surface binding protein and efflux systems are shown (left to right) with arrows to indicate the flow of metals through the cell. Information at the bottom indicates whether the strain is symbiotic with host plants $\left(\mathrm{Sym}^{+-}\right)$, is a diazotroph $\left(\mathrm{N}_{2}-\mathrm{fix} \mathrm{X}^{+-}\right)$, and whether the strain is resistant (r) or sensitive (s) to a particular metal. ${ }^{*}=$ DRAFT.

Additional file 18: Frankia sp. strain DC12 metal homeostasis mechanisms. Schematic diagram of known and putative metal homeostasis systems in Frankia sp. strain DC12. Loci containing identifying domains (see Additional file 10) for metal ion uptake transporters, chaperones, modification enzymes, efflux transporters, and surface binding protein and efflux systems are shown (left to right) with arrows to indicate the flow of metals through the cell. Information at the bottom indicates whether the strain is symbiotic with host plants $\left(\mathrm{Sym}^{+/}\right)$, is a diazotroph $\left(\mathrm{N}_{2}-\mathrm{fix}{ }^{+/}\right)$, and whether the strain is resistant (r) or sensitive (s) to a particular metal. * $=$ DRAFT

Additional file 19: Confirmation of Frankia resistance and reduction of tellurite based on genome prediction. Frankia sp. strain $\mathrm{Ccl} 3$ was grown on solid minimal media containing either [A] $0 \mathrm{mM}$ or [B] $3 \mathrm{mM}$ potassium tellurite. As predicted by the presence of several tellurite resistance and reduction factors in the Frankia genome, strain $\mathrm{CCl} 3$ was able to grow in the presence of tellurite and reduce it to elemental tellurium (black precipitate).

\section{Additional file 20: Phylogenetic analysis of the MerR family} proteins in Frankia. Neighbor-joining tree of Clustal $\Omega$ aligned MerR proteins (COG0789) containing protein sequences from Frankia, Bacillus subtilis subtilis 168, Escherichia coli K12-W3110, and Cupriavidus metallidurans $\mathrm{CH} 34$. The ten clusters of Frankia MerR proteins comprise two distinct group of metal and non-metal regulators. Underlined genes were upregulated with the indicated metals from the compiled gene array studies (see Additional file 1). Asterisk indicates the conservation of a motif. ([LIV][SADG][DER].....[DEGA].\{3,4\}[^S].[LIV][DR][FHDCY]Y \{3,4\}GL[LIVMF]. $\left.\left.{ }^{*} \wedge \mathrm{Q}\right][\mathrm{GR}] .[\mathrm{FY}] . .[\wedge \mathrm{H}]\right)$ derived from protein sequence alignment of the upregulated MerR array genes.

Additional file 21: Phylogenetic analysis of the ArsR family proteins in Frankia. Neighbor-joining tree of Clustal $\Omega$ aligned ArsR proteins (COG0640) containing protein sequences from Frankia, upregulated genes from the compiled array data (Additional file 1), and characterized ArsR-family proteins. The metals that induced up-regulation of the gene from the array studies are listed next to the gene. The five clusters of Frankia ArsR proteins include 1. a group with no similarity to characterized ArsR proteins, 2. a group that is in a potential operon with the cation diffusion facilitor $(\mathrm{CzCD})$, 3. a group that is in a potential operon with the activator of heat shock 90 ATPase protein (AHSA), 4. a group highly similar to the M. tuberculosis nickel responsive repressor (NmtR), and 5. a group in a potential ars operon with other arsenic resistance genes.

Additional file 22: Phylogenetic analysis of the CsoR family proteins in Frankia. Neighbor-joining tree of Clustal $\Omega$ aligned CsoR proteins (pfam02583) containing protein sequences from Frankia, characterized members of CsoR-family, and proteins from the 18 comparative organisms (Additional file 10). 1. Uncharacterized CsoR-like proteins. 2. True CsoR proteins. The synteny between characterized CsoR (BSU33420) and the other orthologs is displayed, showing the regulatory target, copper-exporting CopA. 3. Copper regulating RicR proteins.

Additional file 23: Phylogenetic analysis of the Fur family proteins in Frankia. Neighbor-joining tree of Clustal $\Omega$ aligned MerR proteins (KO:K03711) containing protein sequences from Frankia, and the 18 comparative organisms (Additional file 10). Representative neighborhoods are included to demonstrate synteny of the 4 regulators (Fur, Nur, PerR, Zur) in Frankia. Arrows indicate the regulators and their targets. Asterisks indicate characterized proteins.

Additional file 24: Methodology workflow chart. Breakdown of the process for identification of metal homeostasis mechanisms used in this study.

\section{Competing interests}

The authors declare that they have no competing interests.

\section{Authors' contributions}

TRF Carried out the comparative genome analysis of metal homeostasis mechanisms, the figure creations, gene data compilation, meta-analysis of heavy metal global gene array studies from the literature, and drafted the manuscript. LST Guided data acquisition methodology and critically revised the intellectual content of the manuscript for submission. Both authors have read and approved the final manuscript.

\section{Acknowledgements}

This project (LST) was supported in part by Hatch grant NH585, USDA NIFA 2010-65108-20581, National Science Foundation Grant No. EF-0333177, and the College of Life Sciences and Agriculture (COLSA) at the University of New Hampshire, Durham, NH. This is scientific contribution number 2562 from the NH Agricultural Experimental Station.

Received: 30 June 2014 Accepted: 19 November 2014 Published: 12 December 2014

\section{References}

1. Chaia EE, Wall LG, Huss-Danell K: Life in soil by actinorhizal root nodule endophyte Frankia. a review. Symbiosis 2010, 51(3):201-226.

2. Santi C, Bogusz D, Franche C: Biological nitrogen fixation in non-legume plants. Ann Bot 2013, 111(5):743-767.

3. Benson DR, Dawson JO: Recent advances in the biogeography and genecology of symbiotic Frankia and its host plants. Physiol Plant 2007, 130(3):318-330.

4. Schwencke J, Carú M: Advances in actinorhizal symbiosis: host plantFrankia interactions, biology, and applications in arid land reclamation: a review. Arid Land Res Manag 2001, 15(4):285-327.

5. Richards JW, Krumholz GD, Chval MS, Tisa LS: Heavy metal resistance patterns of Frankia strains. Appl Environ Microbiol 2002, 68(2):923-927.

6. Monsieurs P, Moors H, Van Houdt R, Janssen PJ, Janssen A, Coninx I, Leys N: Heavy metal resistance in Cupriavidus metallidurans $\mathrm{CH} 34$ is governed by an intricate transcriptional network. Biometals 2011, 24(6):1133-1151.

7. Alford ÉR, Pilon-Smits EA, Paschke MW: Metallophytes-a view from the rhizosphere. Plant Soil 2010, 337(1-2):33-50.

8. Maret W: Metalloproteomics, metalloproteomes, and the annotation of metalloproteins. Metallomics 2010, 2(2):117-125.

9. Baker D, Torrey JG: The Isolation and Cultivation of Actinomycetous Root Nodule Endophytes. In Symbiotic Nitrogen Fixation in the Management of Temperate Forests. Edited by Gordon JC, Wheeler CT, Perry DA. Corvalis: Oregon State University Press; 1979:38-56.

10. Sayed WF, Mohaowad SM, El-Karim MA: Effect of Al, $\mathrm{Co}$, and $\mathrm{Pb}$ ions on growth of Frankia spp. in a mineral medium. Folia Microbiol 2000, 45(2):153-156.

11. Singh A, Singh SS, Pandey PC, Mishra AK: Attenuation of metal toxicity by Frankial siderophores. Toxicol Environ Chem 2010, 92(7):1339-1346.

12. Diagne N, Arumugam K, Ngom M, Nambiar-Veetil M, Franche C, Narayanan KK, Laplaze L: Use of Frankia and actinorhizal plants for degraded lands reclamation. Biomed Res Int 2013, 2013:948258.

13. Laplaze L, Gherbi H, Duhoux E, Pawlowski K, Auguy F, Guermache F, Bogusz D: Symbiotic and non-symbiotic expression of cgMT1, a metallothionein-like gene from the actinorhizal tree Casuarina glauca. Plant Mol Biol 2002, 49(1):81-92. 
14. Ridgway KP, Marland LA, Harrison AF, Wright J, Young JPW, Fitter AH: Molecular diversity of Frankia in root nodules of Alnus incana grown with inoculum from polluted urban soils. FEMS Microbiol Ecol 2004 50(3):255-263

15. Sayed WF: Effects of land irrigation with partially-treated wastewater on Frankia survival and infectivity. Plant Soil 2003, 254(1):19-25.

16. Wheeler CT, Miller IM: Current and Potential Uses of Actinorhizal Plants in Europe. In The Biology of Frankia and Actinorhizal Plants. Edited by Schwintzer CR, Tjepkema JD. New York: Academic Press; 1990:365-389.

17. Bayle L, Chimalapati S, Schoehn G, Brown J, Vernet T, Durmort C: Zinc uptake by Streptococcus pneumoniae depends on both AdcA and AdcAll and is essential for normal bacterial morphology and virulence. Mol Microbiol 2011, 82(4):904-916.

18. Lemire JA, Harrison JJ, Turner RJ: Antimicrobial activity of metals: mechanisms, molecular targets and applications. Nat Rev Microbiol 2013, 11(6):371-384.

19. Marcus Y: lonic radii in aqueous solutions. Chem Rev 1988, 88(8):1475-1498.

20. Nies DH: Efflux-mediated heavy metal resistance in prokaryotes. FEMS Microbiol Rev 2003, 27(2-3):313-339.

21. Blaby-Haas CE, Merchant SS: The ins and outs of algal metal transport. Biochim Biophys Acta 2012, 1823(9):1531-1552.

22. Tisa LS, Beauchemin N, Gtari M, Sen A, Wall LG: What stories can the Frankia genomes start to tell us? J Biosci 2013, 38(4):719-726.

23. Normand P, Lapierre P, Tisa LS, Gogarten JP, Alloisio N, Bagnarol E, Benson DR Genome characteristics of facultatively symbiotic Frankia sp. strains reflect host range and host plant biogeography. Genome Res 2007, 17(1):7-15.

24. Ghodhbane-Gtari F, Beauchemin N, Bruce D, Chain P, Chen A, Davenport KW, Tisa LS: Draft genome sequence of Frankia sp. strain CN3, an atypical, noninfective (Nod-) ineffective (Fix-) isolate from Coriaria nepalensis. Genome Announc 2013, 1(2):e00085-13.

25. Persson T, Benson DR, Normand P, Heuvel BV, Pujic P, Chertkov O, Berry AM: Genome sequence of "Candidatus Frankia datiscae" Dg1, the uncultured microsymbiont from nitrogen-fixing root nodules of the dicot Datisca glomerata. J Bacterio/ 2011, 193(24):7017-7018.

26. Sen A, Beauchemin N, Bruce D, Chain P, Chen A, Davenport KW, Tisa LS: Draft genome sequence of Frankia sp. strain QA3, a nitrogen-fixing actinobacterium isolated from the root nodule of Alnus nitida. Genome Announc 2013, 1(2):e00103-e00113.

27. Wall LG, Beauchemin N, Cantor MN, Chaia E, Chen A, Detter JC, Furnholm T, Ghodhbane-Gtari F, Goodwin L, Gtari M, Han C, Han J, Huntemann M, Hua SX, Ivanova N, Kyrpides N, Markowitz V, Mavrommatis K, Mikhalova N, Nordberg HP, Nouioui I, Ovchinnikova G, Pagani I, Pati A, Sen A, Sur S, Szeto E, Thakur S, Wei CL, Woyke T, et al: Draft genome sequence of Frankia sp. strain BCU110501, a nitrogen-fixing actinobacterium isolated from nodules of Discaria trinevis. Genome Announc 2013, 1(4):e00503-e00513.

28. Nouioui I, Beauchemin N, Cantor MN, Chen A, Detter JC, Furnholm T, Ghodhbane-Gtari F, Goodwin L, Gtari M, Han C, Han J, Huntemann M, Hua SX, Ivanova N, Kyrpides N, Markowitz V, Mavrommatis K, Mikhalova N, Nordberg HP, Ovchinnikova G, Pagani I, Pati A, Sen A, Sur S, Szeto E, Thakur S, Wall L, Wei CL, Woyke T, Tisa LS: Draft genome sequence of Frankia sp. strain BMG5. 12, a nitrogen-fixing actinobacterium isolated from Tunisian soils. Genome Announc 2013, 1(4):e00468-13.

29. Mansour SR, Oshone R, Hurst SG IV, Morris K, Thomas WK, Tisa LS: Draft genome sequence of Frankia sp. strain Ccl6, a salt-tolerant ntrogen-fixing actinobacterium isolated from the root nodule of Casuarina cunninghamiana. Genome Announc 2014, 2(3):e01205-e01213.

30. Hurst SG IV, Ghodhbane-Gtari F, Oshone R, Morris K, Abebe-Akele F, Thomas WK, Ktari A, Salem K, Mansour S, Gtari M, Tisa LS: Draft genome sequence of Frankia sp. strain Thr, a nitrogen-fixing actinobacterium isolated from the root nodules of Casuarina cunninghamiana grown in Egypt. Genome Announc 2014, 2(3):e00493-14.

31. Ghodhbane-Gtari F, Hurst SG IV, Oshone R, Morris K, Abebe-Akele F, Thomas WK, Ktari A, Salem K, Gtari M, Tisa LS: Draft genome sequence of Frankia sp. strain BMG5. 23, a salt-tolerant ntrogen-fixing actinobacterium isolated from the root nodule of Casuarina glauca grown in Tunisia. Genome Announc 2014, 2(3):e00520-14.

32. Niemann J, Tisa LS: Nitric oxide and oxygen regulate truncated hemoglobin gene expression in Frankia strain Ccl3. J Bacterio/ 2008, 190(23):7864-7867.

33. Perrine-Walker F, Doumas P, Lucas M, Vaissayre V, Beauchemin NJ, Band LR, Laplaze L: Auxin carriers localization drives auxin accumulation in plant cells infected by Frankia in Casuarina glauca actinorhizal nodules. Plant Physiol 2010, 154(3):1372-1380.
34. Nouioui I, Ghodhbane-Gtari F, Beauchemin NJ, Tisa LS, Gtari M: Phylogeny of members of the Frankia genus based on gyrB, nifH and glnll sequences. Antonie Van Leeuwenhoek 2011, 100(4):579-587.

35. Mastronunzio JE, Tisa LS, Normand P, Benson DR: Comparative secretome analysis suggests low plant cell wall degrading capacity in Frankia symbionts. BMC Genomics 2008, 9(1):47.

36. Sen A, Sur S, Bothra AK, Benson DR, Normand P, Tisa LS: The implication of life style on codon usage patterns and predicted highly expressed genes for three Frankia genomes. Antonie Van Leeuwenhoek 2008, 93(4):335-346.

37. Udwary DW, Gontang EA, Jones AC, Jones CS, Schultz AW, Winter JM, Moore BS: Significant natural product biosynthetic potential of actinorhizal symbionts of the genus Frankia, as revealed by comparative genomic and proteomic analyses. Appl Environ Microbiol 2011, 77(11):3617-3625.

38. Alloisio N, Queiroux C, Fournier P, Pujic P, Normand P, Vallenet D, Kucho Kl: The Frankia alni symbiotic transcriptome. Mol Plant Microbe Interact 2010, 23(5):593-607.

39. Popovici J, Comte G, Bagnarol É, Alloisio N, Fournier P, Bellvert F, Fernandez MP: Differential effects of rare specific flavonoids on compatible and incompatible strains in the Myrica gale-Frankia actinorhizal symbiosis. Appl Environ Microbiol 2010, 76(8):2451-2460.

40. Lee HI, Donati AJ, Hahn D, Tisa LS, Chang WS: Alterations of the exopolysaccharide production and transcriptional profile of Frankia strain $\mathrm{Ccl} 3$ under nitrogen-fixing conditions. Appl Microbiol Biotechnol 2013, 97(24):10499-10509.

41. Alloisio N, Félix S, Maréchal J, Pujic P, Rouy Z, Vallenet D, Normand P. Frankia alni proteome under nitrogen-fixing and nitrogen-replete conditions. Physiol Plant 2007, 130(3):440-453.

42. Bagnarol E, Popovici J, Alloisio N, Maréchal J, Pujic P, Normand P, Fernandez MP: Differential Frankia protein patterns induced by phenolic extracts from Myricaceae seeds. Physiol Plant 2007, 130(3):380-390.

43. Mastronunzio JE, Huang Y, Benson DR: Diminished exoproteome of Frankia spp. in culture and symbiosis. Appl Environ Microbiol 2009, 75(21):6721-6728.

44. Mastronunzio JE, Benson DR: Wild nodules can be broken: proteomics of Frankia in field-collected root nodules. Symbiosis 2010, 50(1-2):13-26.

45. Andrews SC, Robinson AK, Rodríguez-Quiñones F: Bacterial iron homeostasis. FEMS Microbiol Rev 2003, 27(2-3):215-237.

46. Jakubovics NS, Jenkinson HF: Out of the iron age: new insights into the critical role of manganese homeostasis in bacteria. Microbiology 2001, 147(7):1709-1718.

47. Zhang Y, Gladyshev VN: General trends in trace element utilization revealed by comparative genomic analyses of $\mathrm{Co}, \mathrm{Cu}, \mathrm{Mo}, \mathrm{Ni}$, and $\mathrm{Se}$. J Biol Chem 2010, 285(5):3393-3405.

48. Braun V, Hantke K: Recent insights into iron import by bacteria. Curr Opin Chem Biol 2011, 15(2):328-334.

49. Arahou M, Diem HG, Sasson A: Influence of iron depletion on growth and production of catechol siderophores by different Frankia strains. World J Microbiol Biotechnol 1997, 14(1):31-36.

50. Aronson DB, Boyer GL: Frankia produces a hydroxamate siderophore under iron limitation. J Plant Nutr 1992, 15(10):2193-2201.

51. Tjepkema JD, Cashon RE, Beckwith J, Schwintzer CR: Hemoglobin in Frankia, a nitrogen-fixing actinomycete. Appl Environ Microbiol 2002, 68(5):2629-2631.

52. Laplaze L, Gherbi H, Frutz T, Pawlowski K, Franche C, Macheix JJ, Duhoux E: Flavan-containing cells delimit Frankia-infected compartments in Casuarina glauca nodules. Plant Physiol 1999, 121(1):113-122.

53. Bolaños L, Lukaszewski K, Bonilla I, Blevins D: Why boron? Plant Physiol Biochem 2004, 42(11):907-912.

54. Weerasinghe AJ, Amin SA, Barker RA, Othman T, Romano AN, Parker Siburt CJ, Crumbliss AL: Borate as a synergistic anion for Marinobacter algicola ferric binding protein, FbpA: a role for boron in iron transport in marine life. J Am Chem Soc 2013, 135(39):14504-14507.

55. Touati D, Jacques M, Tardat B, Bouchard L, Despied S: Lethal oxidative damage and mutagenesis are generated by iron in delta fur mutants of Escherichia coli: protective role of superoxide dismutase. J Bacteriol 1995, 177(9):2305-2314.

56. Hammad Y, Marechal J, Cournoyer B, Normand P, Domenach AM: Modification of the protein expression pattern induced in the nitrogen-fixing actinomycete Frankia sp. strain ACN14a-tsr by root exudates of its symbiotic host Alnus glutinosa and cloning of the sodF gene. Can J Microbiol 2001, 47(6):541-547.

57. Wang W, Huang $H$, Tan G, Si F, Min L, Landry AP, Ding H: In vivo evidence for the iron binding activity of an iron-sulfur cluster assembly protein IscA in Escherichia coli. Biochem J 2010, 432(3):429. 
58. Grass G, Otto M, Fricke B, Haney CJ, Rensing C, Nies DH, Munkelt D: FieF (YiiP) from Escherichia coli mediates decreased cellular accumulation of iron and relieves iron stress. Arch Microbio/ 2005 183(1):41900.

59. Blencowe DK, Morby AP: Zn (II) metabolism in prokaryotes. FEMS Microbiol Rev 2003, 27(2-3):291-311.

60. Maret W, Li Y: Coordination dynamics of zinc in proteins. Chem Rev 2009, 109(10):4682-4707.

61. Cotruvo JA Jr, Stubbe J: Metallation and mismetallation of iron and manganese proteins in vitro and in vivo: the class I ribonucleotide reductases as a case study. Metallomics 2012, 4(10):1020-1036.

62. Nies DH: Microbial heavy-metal resistance. Appl Microbiol Biotechnol 1999, 51(6):730-750

63. Riccardi G, Milano A, Pasca MR, Nies DH: Genomic analysis of zinc homeostasis in Mycobacterium tuberculosis. FEMS Microbiol Lett 2008, 287(1):41646.

64. Haas CE, Rodionov DA, Kropat J, Malasarn D, Merchant SS, de Crécy-Lagard $V$ : A subset of the diverse COG0523 family of putative metal chaperones is linked to zinc homeostasis in all kingdoms of life. BMC Genomics 2009, 10(1):470.

65. Montanini B, Blaudez D, Jeandroz S, Sanders D, Chalot M: Phylogenetic and functional analysis of the Cation Diffusion Facilitator (CDF) family: improved signature and prediction of substrate specificity. BMC Genomics 2007, 8(1):107.

66. Jia S, Wang Z, Zhang XX, Liu B, Li W, Cheng S: Metagenomic analysis of cadmium and copper resistance genes in activated sludge of a tannery wastewater treatment plant. J Environ Public Health 2013, 34(2SpecNo):375-380.

67. Delhaize E, Gruber BD, Pittman JK, White RG, Leung H, Miao Y, Richardson AE: A role for the AtMTP11 gene of Arabidopsis in manganese transport and tolerance. Plant J 2007, 51(2):198-210.

68. Rosch JW, Gao G, Ridout G, Wang YD, Tuomanen El: Role of the manganese efflux system $m n t E$ for signaling and pathogenesis in Streptococcus pneumoniae. Mol Microbiol 2009, 72(1):41998.

69. Li Y, Zamble DB: Nickel homeostasis and nickel regulation: an overview. Chem Rev 2009, 109(10):4617-4643.

70. Okamoto S, Eltis LD: The biological occurrence and trafficking of cobalt. Metallomics 2011, 3(10):963-970.

71. Ridge PG, Zhang Y, Gladyshev VN: Comparative genomic analyses of copper transporters and cuproproteomes reveal evolutionary dynamics of copper utilization and its link to oxygen. PLoS One 2008, 3(1):e1378.

72. Schwarz G, Mendel RR, Ribbe MW: Molybdenum cofactors, enzymes and pathways. Nature 2009, 460(7257):839-847.

73. Aguilar-Barajas E, Díaz-Pérez C, Ramírez-Díaz MI, Riveros-Rosas H, Cervantes C: Bacterial transport of sulfate, molybdate, and related oxyanions. Biometals 2011, 24(4):687-707.

74. Stolz JF, Basu P, Santini JM, Oremland RS: Arsenic and selenium in microbial metabolism. Annu Rev Microbiol 2006, 60:107.

75. Shepherd M, Heath MD, Poole RK: NikA binds heme: a new role for an Escherichia coli periplasmic nickel-binding protein. Biochemistry 2007, 46(17):5030-5037.

76. Waldron KJ, Robinson NJ: How do bacterial cells ensure that metalloproteins get the correct metal? Nat Rev Microbiol 2009, 7(1):25-35

77. Macomber L, Hausinger RP: Mechanisms of nickel toxicity in microorganisms. Metallomics 2011, 3(11):1153-1162.

78. Iwig JS, Rowe JL, Chivers PT: Nickel homeostasis in Escherichia coli-the rcnR-rcnA efflux pathway and its linkage to NikR function. Mol Microbiol 2006, 62(1):252-262.

79. Mendel RR, Smith AG, Marquet A, Warren MJ: Metal and cofactor insertion. Nat Prod Rep 2007, 24(5):963-971.

80. Berry AM, Harriott OT, Moreau RA, Osman SF, Benson DR, Jones AD: Hopanoid lipids compose the Frankia vesicle envelope, presumptive barrier of oxygen diffusion to nitrogenase. Proc Natl Acad Sci U S A 1993, 90(13):6091-6094.

81. Rubino JT, Franz KJ: Coordination chemistry of copper proteins: how nature handles a toxic cargo for essential function. J Inorg Biochem 2012, 107(1):129-143.

82. Jothivasan VK, Hamilton CJ: Mycothiol: synthesis, biosynthesis and biological functions of the major low molecular weight thiol in actinomycetes. Nat Prod Rep 2008, 25(6):1091-1117.

83. Solioz M, Abicht HK, Mermod M, Mancini S: Response of Gram-positive bacteria to copper stress. J Biol Inorg Chem 2010, 15(1):41712.
84. Chillappagari S, Miethke M, Trip H, Kuipers OP, Marahiel MA: Copper acquisition is mediated by $\mathrm{YcnJ}$ and regulated by $\mathrm{YcnK}$ and $\mathrm{CsoR}$ in Bacillus subtilis. J Bacteriol 2009, 191(7):2362-2370.

85. Taguchi S, Ogawa T, Endo T, Momose H: Identification of a structural gene encoding a metallothionein-like domain that includes a putative regulator protein for Streptomyces protease gene expression. Biosci Biotechnol Biochem 1998, 62(12):2476-2479.

86. Magnani D, Solioz M: How Bacteria Handle Copper. In Molecular Microbiology of Heavy Metals. Edited by Nies DH, Silver S. Berlin: Springer; 2007:259-285.

87. Raimunda D, González-Guerrero M, Leeber BW, Argüello JM: The transport mechanism of bacterial $\mathrm{Cu}+-$-ATPases: distinct efflux rates adapted to different function. Biometals 2011, 24(3):467-475.

88. Chillappagari S: Characterization of copper mediated transcriptional responses in Bacillus subtilis and identification of copper and iron connection in Bacillus subtilis, PhD thesis. Fachbereich Biologie: Philipps-Universität Marburg; 2009.

89. Navarro CA, Orellana LH, Mauriaca C, Jerez CA: Transcriptional and functional studies of Acidithiobacillus ferrooxidans genes related to survival in the presence of copper. Appl Environ Microbiol 2009, 75(19):6102-6109.

90. Lyons JA, Aragão D, Slattery O, Pisliakov AV, Soulimane T, Caffrey M: Structural insights into electron transfer in caa3-type cytochrome oxidase. Nature 2012, 487(7408):514-518.

91. Rehan M, Furnholm T, Finethy RH, Chu F, El-Fadly G, Tisa LS: Copper tolerance in Frankia sp. strain Eul1c involves surface binding and copper transport. Appl Microbiol Biotechnol 2014, 98(18):8005-8015.

92. Zhang Y, Rump S, Gladyshev VN: Comparative genomics and evolution of molybdenum utilization. Coord Chem Rev 2011, 255(9):1206-1217.

93. Zhang Y, Romero H, Salinas G, Gladyshev VN: Dynamic evolution of selenocysteine utilization in bacteria: a balance between selenoprotein loss and evolution of selenocysteine from redox active cysteine residues. Genome Biol 2006, 7(10):R94.

94. Faulkner MJ, Helmann JD: Peroxide stress elicits adaptive changes in bacterial metal ion homeostasis. Antioxid Redox Signal 2011, 15(1):175-189.

95. Debieux CM, Dridge EJ, Mueller CM, Splatt P, Paszkiewicz K, Knight I, Butler CS: A bacterial process for selenium nanosphere assembly. Proc Natl Acad Sci U S A 2011, 108(33):13480-13485.

96. Rehan M: Genetic activities of actinobacteria, Frankia, for the detoxification mechanisms of two heavy metals and the biodegradation of aromatic coumpunds in addition to its bioremediation potential. PhD thesis. Kafrelsheikh Unversity, Department of Genetics; 2012

97. Ordóñez E, Van Belle K, Roos G, De Galan S, Letek M, Gil JA, Wyns L, Mateos $L M$, Messens J: Arsenate reductase, mycothiol, and mycoredoxin concert thiol/disulfide exchange. J Biol Chem 2009, 284(22):15107-15116.

98. Tamura T, Sato K, Komori K, Imai T, Kuwahara M, Okugochi T, Inagaki K: Selenite reduction by the thioredoxin system: kinetics and identification of protein-bound selenide. Bioscience 2011, 75(6):1184.

99. Hemann C, Hood BL, Fulton M, Hänsch R, Schwarz G, Mendel RR, Hille R: Spectroscopic and kinetic studies of Arabidopsis thaliana sulfite oxidase: nature of the redox-active orbital and electronic structure contributions to catalysis. J Am Chem Soc 2005, 127(47):16567-16577.

100. Slyemi D, Bonnefoy V: How prokaryotes deal with arsenic. Environ Microbiol Rep 2012, 4(6):571-586.

101. Rosen BP: Biochemistry of arsenic detoxification. FEBS Lett 2002, 529(1):86-92

102. Wu B, Song J, Beitz E: Novel channel enzyme fusion proteins confer arsenate resistance. J Bioinform Comput Biol 2010, 285(51):40081-40087.

103. Hossain MA, Piyatida P, da Silva JAT, Fujita M: Molecular mechanism of heavy metal toxicity and tolerance in plants: central role of glutathione in detoxification of reactive oxygen species and methylglyoxal and in heavy metal chelation. J Bot 2012, 2012:37.

104. Hotter GS, Wilson T, Collins DM: Identification of a cadmium-induced gene in Mycobacterium bovis and Mycobacterium tuberculosis. FEMS Microbiol Lett 2001, 200(2):151-155.

105. Zhang YB, Monchy S, Greenberg B, Mergeay M, Gang O, Taghavi S, van der Lelie D: ArsR arsenic-resistance regulatory protein from Cupriavidus metallidurans CH34. Antonie Van Leeuwenhoek 2009, 96(2):161-170.

106. Yang HC, Cheng J, Finan TM, Rosen BP, Bhattacharjee H: Novel pathway for arsenic detoxification in the legume symbiont Sinorhizobium meliloti. J Bacteriol 2005, 187(20):6991-6997. 
107. Ramírez-Díaz Ml, Díaz-Pérez C, Vargas E, Riveros-Rosas H, Campos-García J, Cervantes C: Mechanisms of bacterial resistance to chromium compounds. Biometals 2008, 21(3):321-332.

108. Morais PV, Branco R, Francisco R: Chromium resistance strategies and toxicity: what makes Ochrobactrum tritici 5 bvl1 a strain highly resistant. Biometals 2011, 24(3):401-410.

109. Henne KL, Nakatsu CH, Thompson DK, Konopka AE: High-level chromate resistance in Arthrobacter sp. strain FB24 requires previously uncharacterized accessory genes. BMC Microbio/ 2009, 9(1):199

110. Juhnke S, Peitzsch N, Hübener N, Große C, Nies DH: New genes involved in chromate resistance in Ralstonia metallidurans strain $\mathrm{CH} 34$. Arch Microbiol 2002, 179(1):15-25.

111. Krepkiy D, Antholine WE, Petering DH: Properties of the reaction of chromate with metallothionein. Chem Res Toxicol 2003, 16(6):750-756.

112. Schmidt A, Hagen M, Schütze E, Schmidt A, Kothe E: In silico prediction of potential metallothioneins and metallohistins in actinobacteria. J Basic Microbiol 2010, 50(6):562-569.

113. Kirberger M, Wong HC, Jiang J, Yang JJ: Metal toxicity and opportunistic binding of $\mathrm{Pb} 2+$ in proteins. J Inorg Biochem 2013, 125:40-49.

114. Borremans B, Hobman JL, Provoost A, Brown NL, van Der Lelie D: Cloning and functional analysis of the $p b r$ lead resistance determinant of Ralstonia metallidurans CH34. J Bacteriol 2001, 183(19):5651-5658.

115. Naik MM, Dubey SK: Lead resistant bacteria: lead resistance mechanisms, their applications in lead bioremediation and biomonitoring. Ecotoxicol Environ Saf 2013, 98:41646.

116. Furnholm T: Physiology and genetics of lead resistance in Frankia. PhD thesis. University of New Hampshire, Molecular, Cellular, and Biomedical Sciences; 2014

117. Rajkumar M, Ae N, Prasad MNV, Freitas H: Potential of siderophore-producing bacteria for improving heavy metal phytoextraction. Trends Biotechnol 2010, 28(3):142-149.

118. Shin MN, Shim J, You Y, Myung H, Bang KS, Cho M, Oh BT: Characterization of lead resistant endophytic Bacillus sp. MN3-4 and its potential for promoting lead accumulation in metal hyperaccumulator Alnus firma. J Hazard Mater 2012, 199:314-320.

119. Levinson HS, Mahler I: Phosphatase activity and lead resistance in Citrobacter freundii and Staphylococcus aureus. FEMS Microbiol Lett 1998, 161(1):135-138.

120. Davis AK, Hildebrand M, Palenik B: Gene expression induced by copper stress in the diatom Thalassiosira pseudonana. Eukaryot Cell 2006, 5(7):1157-1168.

121. Turner RJ, Borghese R, Zannoni D: Microbial processing of tellurium as a tool in biotechnology. Biotechnol Adv 2012, 30(5):954-963.

122. Elías AO, Abarca MJ, Montes RA, Chasteen TG, Pérez-Donoso JM, Vasquez CC: Tellurite enters Escherichia coli mainly through the PitA phosphate transporter. Microbiology Open 2012, 1(3):259-267.

123. Tian W: The Biological Metabolism of Nitrate and Nitrite in Pseudomonas Fluorescens K27 amended with Tellurium. In Masters Thesis. Sam Houston State University: Department of Chemistry; 2004

124. Chasteen TG, Fuentes DE, Tantaleán JC, Vásquez CC: Tellurite: history, oxidative stress, and molecular mechanisms of resistance. FEMS Microbiol Rev 2009, 33(4):820-832.

125. Aradská J, Šmidák R, Turkovičová L, Turňa J, Lubec G: Proteomic differences between tellurite-sensitive and tellurite-resistant E. coli. PLoS One 2013, 8(11):e78010.

126. Chen PR, He C: Selective recognition of metal ions by metalloregulatory proteins. Curr Opin Chem Biol 2008, 12(2):214-221.

127. Brown NL, Stoyanov JV, Kidd SP, Hobman JL: The MerR family of transcriptional regulators. FEMS Microbiol Rev 2003, 27(2-3):145-163.

128. Kustu S, Burton D, Garcia E, McCarter L, McFarland N: Nitrogen control in Salmonella: regulation by the $g \ln R$ and $g \operatorname{lnF}$ gene products. Proc Natl Acad Sci U S A 1979, 76(9):4576-4580

129. Busenlehner LS, Pennella MA, Giedroc DP: The SmtB/ArsR family of metalloregulatory transcriptional repressors: structural insights into prokaryotic metal resistance. FEMS Microbiol Rev 2003, 27(2-3):131-143.

130. Wang $Y$, Hemmingsen L, Giedroc DP: Structural and functional characterization of Mycobacterium tuberculosis CmtR, a Pbll/Cdll-sensing SmtB/ArsR metalloregulatory repressor. Biochemistry 2005, 44(25):8976-8988.

131. Kim JS, Kang SO, Lee JK: The protein complex composed of nickel-binding SrnQ and DNA binding motif-bearing SrnR of Streptomyces griseus represses sodF transcription in the presence of nickel. J Biol Chem 2003, 278(20):18455-18463.

132. Ma Z, Cowart DM, Scott RA, Giedroc DP: Molecular insights into the metal selectivity of the copper (I)-sensing repressor CsoR from Bacillus subtilis. Biochemistry 2009, 48(15):3325-3334

133. Higgins KA, Giedroc D: Insights into protein allostery in the $\mathrm{CsoR} / \mathrm{RcnR}$ family of transcriptional repressors. Chem Lett 2014, 43(1):20.

134. Festa RA, Jones MB, Butler-Wu S, Sinsimer D, Gerads R, Bishai WR, Darwin $\mathrm{KH}$ : A novel copper-responsive regulon in Mycobacterium tuberculosis. Mol Microbiol 2011, 79(1):133-148.

135. Rubio-Sanz L, Prieto RI, Imperial J, Palacios JM, Brito B: Functional and expression analysis of the metal-inducible dmeRF system from Rhizobium leguminosarum bv. viciae. App/ Environ Microbio/ 2013, 79(20):6414-6422.

136. Reyes-Caballero H, Lee CW, Giedroc DP: Mycobacterium tuberculosis NmtR harbors a nickel sensing site with parallels to Escherichia coli RcnR. Biochemistry 2011, 50(37):7941-7952.

137. Ma Z, Faulkner MJ, Helmann JD: Origins of specificity and cross-talk in metal ion sensing by Bacillus subtilis Fur. Mol Microbio/ 2012, 86(5):1144-1155.

138. Santos CL, Vieira J, Tavares F, Benson DR, Tisa LS, Berry AM, Moradas-Ferreira P, Normand P: On the nature of fur evolution: a phylogenetic approach in Actinobacteria. BMC Evol Biol 2008, 8(1):185

139. Ahn BE, Cha J, Lee EJ, Han AR, Thompson CJ, Roe JH: Nur, a nickel-responsive regulator of the Fur family, regulates superoxide dismutases and nickel transport in Streptomyces coelicolor. Mol Microbio/ 2006, 59(6):1848-1858.

140. An H, Zhou H, Huang Y, Wang G, Luan C, Mou J, Luo Y, Hao Y: High-level expression of heme-dependent catalase gene katA from Lactobacillus sakei protects Lactobacillus rhamnosus from oxidative stress. Mol Biotechnol 2010, 45(2):155-160.

141. Chouchane S, Girotto S, Kapetanaki S, Schelvis JP, Yu S, Magliozzo RS: Analysis of heme structural heterogeneity in Mycobacterium tuberculosis catalase-peroxidase (KatG). J Biol Chem 2003, 278(10):8154-8162.

142. Schröder J, Jochmann N, Rodionov DA, Tauch A: The Zur regulon of Corynebacterium glutamicum ATCC 13032. BMC Genomics 2010, 11(1):12.

143. Canneva F, Branzoni M, Riccardi G, Provvedi R, Milano A: Rv2358 and FurB. two transcriptional regulators from Mycobacterium tuberculosis which respond to zinc. J Bacteriol 2005, 187(16):5837-5840.

144. Jin S, Kurtz DM Jr, Liu ZJ, Rose J, Wang BC: Displacement of iron by zinc at the di-iron site of Desulfovibrio vulgaris rubrerythrin: X-ray crystal structure and anomalous scattering analysis. J Inorg Biochem 2004, 98(5):786-796.

145. Brune I, Werner H, Hüser AT, Kalinowski J, Pühler A, Tauch A: The DtxR protein acting as dual transcriptional regulator directs a global regulatory network involved in iron metabolism of Corynebacterium glutamicum. BMC Genomics 2006, 7(1):21.

146. Guedon E, Helmann JD: Origins of metal ion selectivity in the DtxR/MntR family of metalloregulators. Mol Microbiol 2003, 48(2):495-506.

147. Markowitz VM, Chen IMA, Palaniappan K, Chu K, Szeto E, Grechkin Y, Kyrpides NC: IMG: the integrated microbial genomes database and comparative analysis system. Nucleic Acids Res 2010, 40(D1):115-122.

148. Consortium UP: The universal protein resource (UniProt). Nucleic Acids Res 2008, 36(suppl1):D190-D195.

149. Bateman A, Coin L, Durbin R, Finn RD, Hollich V, Griffiths-Jones S, Eddy SR: The Pfam protein families database. Nucleic Acids Res 2004, 32(suppl1):138-141.

150. Ashburner M, Ball CA, Blake JA, Botstein D, Butler H, Cherry JM, Sherlock G: Gene Ontology: tool for the unification of biology. Nat Genet 2000, 25(1):25-29.

151. Tatusov RL, Galperin MY, Natale DA, Koonin EV: The COG database: a tool for genome-scale analysis of protein functions and evolution. Nucleic Acids Res 2000, 28(1):33-36.

152. Hall TA: BioEdit: a user-friendly biological sequence alignment editor and analysis program for Windows 95/98/NT. Nucleic Acids Symp Ser 1999, 41(1):95-98.

153. Kumar S, Nei M, Dudley J, Tamura K: MEGA: a biologist-centric software for evolutionary analysis of DNA and protein sequences. Brief Bioinform 2008, 9(4):299-306.

doi:10.1186/1471-2164-15-1092

Cite this article as: Furnholm and Tisa: The ins and outs of metal

homeostasis by the root nodule actinobacterium Frankia. BMC Genomics 2014 15:1092. 